\title{
Damage-Associated Molecular Pattern-Triggered Immunity in Plants
}

\author{
Shuguo Hou ${ }^{1 *}$, Zunyong Liu${ }^{2}$, Hexi Shen ${ }^{1}$ and Daoji Wu ${ }^{1 *}$ \\ ${ }^{1}$ School of Municipal and Environmental Engineering, Shandong Jianzhu University, Jinan, China, ${ }^{2}$ State Key Laboratory \\ of Rice Biology, Zhejiang University, Hangzhou, China
}

OPEN ACCESS

Edited by:

Yusuke Saijo,

Nara Institute of Science

and Technology (NAIST), Japan

Reviewed by:

Kiwamu Tanaka,

Washington State University,

United States

Yasuhiro Kadota,

RIKEN Center for Sustainable Resource Science (CSRS), Japan

*Correspondence:

Shuguo Hou

hou_shuguo@126.com

Daoji Wu

wdj@sdjzu.edu.cn

Specialty section:

This article was submitted to

Plant Microbe Interactions,

a section of the journal

Frontiers in Plant Science

Received: 11 February 2019

Accepted: 29 April 2019

Published: 22 May 2019

Citation:

Hou S, Liu Z, Shen H and WU D (2019) Damage-Associated Molecular

Pattern-Triggered Immunity in Plants.

Front. Plant Sci. 10:646.

doi: 10.3389/fpls.2019.00646
As a universal process in multicellular organisms, including animals and plants, cells usually emit danger signals when suffering from attacks of microbes and herbivores, or physical damage. These signals, termed as damage-associated molecular patterns (DAMPs), mainly include cell wall or extracellular protein fragments, peptides, nucleotides, and amino acids. Once exposed on cell surfaces, DAMPs are detected by plasma membrane-localized receptors of surrounding cells to regulate immune responses against the invading organisms and promote damage repair. DAMPs may also act as long-distance mobile signals to mediate systemic wounding responses. Generation, release, and perception of DAMPs, and signaling events downstream of DAMP perception are all rigorously modulated by plants. These processes integrate together to determine intricate mechanisms of DAMP-triggered immunity in plants. In this review, we present an extensive overview on our current understanding of DAMPs in plant immune system.

Keywords: plant immunity, DAMPs, PRRs, receptor-like kinases, systemic resistance

\section{INTRODUCTION}

Plants are constantly assaulted by various pathogens and insect herbivores, which seek to assimilate plant-derived nutrients for their survivals and propagations. Plants have evolved abilities to activate immune responses against invading organisms and promote wound healing. Distinct from mammals, plants lack adaptive immunity and specialized immune cells. They primarily actuate immunity by strengthening existing physical and chemical bulwarks, and activating two types of immune signaling pathways: pattern-triggered immunity (PTI) and effector-triggered immunity (ETI) (Cui et al., 2015; Yu et al., 2017). Local induction of both PTI and ETI often triggers a broadspectrum immunity to subsequent pathogen attacks in distal tissues, a phenomenon called systemic acquired resistance (SAR) (Fu and Dong, 2013).

Pattern-triggered immunity is considered to be the first line of inducible defense in plants. It is canonically triggered through the detection of non-self microbial signatures, which are called pathogen-associated molecular patterns (PAMPs). PAMPs are often highly conserved molecules with representative characteristic of a whole class of microbes and are recognized by plasma membrane-localized pattern recognition receptors (PRRs). PRRs, such as FLAGELLIN SENSING 2 (FLS2) and EF-Tu RECEPTOR (EFR), are mainly transmembrane receptor-like kinases (RLKs) or receptor-like proteins (RLPs). Upon PAMP perception, PRRs associate or dis-associate with their partner proteins to provide a platform for downstream immune signaling, including a rapid burst of $\mathrm{Ca}^{2+}$ and reactive oxygen species (ROS), activation of $\mathrm{Ca}^{2+}$-dependent protein kinases (CDPKs) and mitogen-activated protein kinases (MAPKs), production of phytohormones, and extensive 
transcriptional and metabolic reprogramming (Chinchilla et al., 2007; Heese et al., 2007; Boller and Felix, 2009; Sun et al., 2013; Macho and Zipfel, 2014). ETI, in contrast, is a second layer of inducible defense typically activated by the intracellular recognition of pathogen effector molecules by plant resistance (R) gene products (Cui et al., 2015). ETI is often characterized by localized 'hypersensitive response' (HR), a type of programmed cell death (PCD).

The amplification of immune signals is very important for plants to achieve of disease resistance after when detection of PAMPs in early stages of pathogen invasion. One of the strategies is to rapidly activate immune responses by perceiving some hostderived molecules, named damage-associated molecular patterns (DAMPs), with overlapped PTI signaling components (Lotze et al., 2007; Boller and Felix, 2009). "DAMP” was originally defined in mammalian immune system in the beginning of this century and gradually referred in plant immunity (Seong and Matzinger, 2004; Lotze et al., 2007; Boller and Felix, 2009; Tanaka et al., 2014). By now, many DAMPs were identified and their roles in plant immunity are partially understood (Table 1). Similar to which in mammals, DAMPs in plants are mainly cytosolic proteins, peptide, nucleotides, and amino acids, which are released from damaged cells or secreted by intact cells undergoing pathogen invasion. In addition, some oligomeric fragments of plant cell-wall polysaccharides released when tissues are disrupted by physical injuries or attacks of pathogens and herbivores also function as DAMPs. As the case of PAMPs, DAMPs initiate PRR-mediated immune responses in local sites surrounding of wounding and pathogen invasion and regulate systemic immune signaling (Figure 1). In most cases, however, DAMPs play distinct roles from PAMPs. In this review, we summarize our current understanding of DAMPs in plant immune system, and provide an extensive overview on their molecular structures, generation, release, perception, and signaling events.

\section{CUTICLE AND CELL WALL COMPONENTS}

Cuticles and plant cell walls form outermost physical obstacles encountered by pathogens. Plant cell wall is also one of the major carbon sources for necotrophic pathogens. To penetrate these barriers and assimilate nutrients from plant cells, pathogens devour their hosts by secretion of cutinolytic enzymes and cell wall degrading enzymes (CWDEs) (Kubicek et al., 2014). To counteract such savage enzymatic impacts, plants have evolved strategies to monitor the integrities of cuticles and cell walls through the perception of their degradation products, a group of DAMPs, and activate immune responses.

\section{Cutin Monomers}

Plant cuticles are protecting films covering the epidermal cells of leaves and some other aerial plant organs. The main structural components of plant cuticles are unique polymer cutins. The insoluble polymers built mainly on esterified C16 and C18 hydroxy and epoxy fatty acids, impregnated with wax. Although plant cuticles are thought as efficient mechanical shields against pathogen invasions, they still get infection and penetration due to the secreting cutinases from pathogens (Serrano et al., 2014; Ziv et al., 2018). However, deletion of the cutinases and cutinolytic lipases in some necrotrophic fungus, such as Botrytis cinerea, does not hinder the pathogen to enter intact plant tissues (Reis et al., 2005). On the contrary, Arabidopsis leaves treated with cutinase or overexpressing pathogen cutinase gene display strong resistance toward the necrotrophic fungus $B$. cinerea (Chassot et al., 2007). In addition, mutations in various aspects of plant cutin biosynthesis genes also improve plant resistance to B. cinerea (Kurdyukov et al., 2006; Chassot et al., 2007; Bessire et al., 2011), suggesting that plants may able to activate immunity by monitoring of the cuticle integrity. Exogenous application of cutin monomers to plant leaves or suspensioncultured cells induces defense responses, upregulate expression of defense-related genes, and increase resistance to $B$. cinerea (Fauth et al., 1998; Buxdorf et al., 2014). Thus, it was speculated that plant cuticles could be degraded by pathogen cutinase to cutin monomers, which acting as DAMPs elicit immune responses and elevate pathogen resistance. However, the molecular mechanisms underlying cutin monomer perception and cutin monomerregulated plant immunity remain unclear.

\section{Oligogalacturonic Acid}

Pectin is a major component of plant cell wall matrix. It consists of a diverse group of polysaccharides. Homogalacturonan (HG), a linear homopolymer of $\alpha$-(1-4)-linked D-galacturonic acid (GalA), is the most abundant pectic polysaccharide in primary cell walls. HG is easy to be targeted and hydrolyzed by pathogen or plant-derived HG-digesting enzymes, such as polygalacturonases (PGs) and pectate lyases (PLs), and OGs, the best-known plant HG-derived DAMPs, are expected to be released through the action of these enzymes (Cervone et al., 1989; Norman et al., 1999; Orozco-Cardenas and Ryan, 1999). Exogenous treatment of plants with OGs activates a wide range of defense responses, including the production of ROS (Bellincampi et al., 2000), the activation MAPKs (Galletti et al., 2011), the deposition of callose (Galletti et al., 2008), the accumulation of phytoalexins (Davis et al., 1986; Ferrari et al., 2007), and the expression of defense-related genes (Ferrari et al., 2007). As a result, it enhances the plant resistance to multiple pathogens, such as necrotrophic B. cinerea, Pectobacterium carotovorum, and hemibiotrophic Pseudomonas syringae (Ferrari et al., 2007; Benedetti et al., 2015; Davidsson et al., 2017). It was reported that the generation of elicitor-active OGs during microbial infections is promoted by plant-encoded PG-inhibiting proteins (PGIPs), which block the complete hydrolysis of $\mathrm{HG}$ to galacturonic acid (Benedetti et al., 2015), suggesting that OGs are generated on condition of partial inhibition of pathogen-encoded PGs. The elicitor-active OGs were predicted to be a complex of oligomers with a degree of GalA polymerization between 10 and 15 (Cote and Hahn, 1994; Federici et al., 2006; Ferrari et al., 2007). Recently, it was indicated that trimeric OGs also induced plant immune responses and enhanced pathogen resistance similar to long OGs (Davidsson et al., 2017). However, the expression of immune-related genes induced by trimers was overall lower 


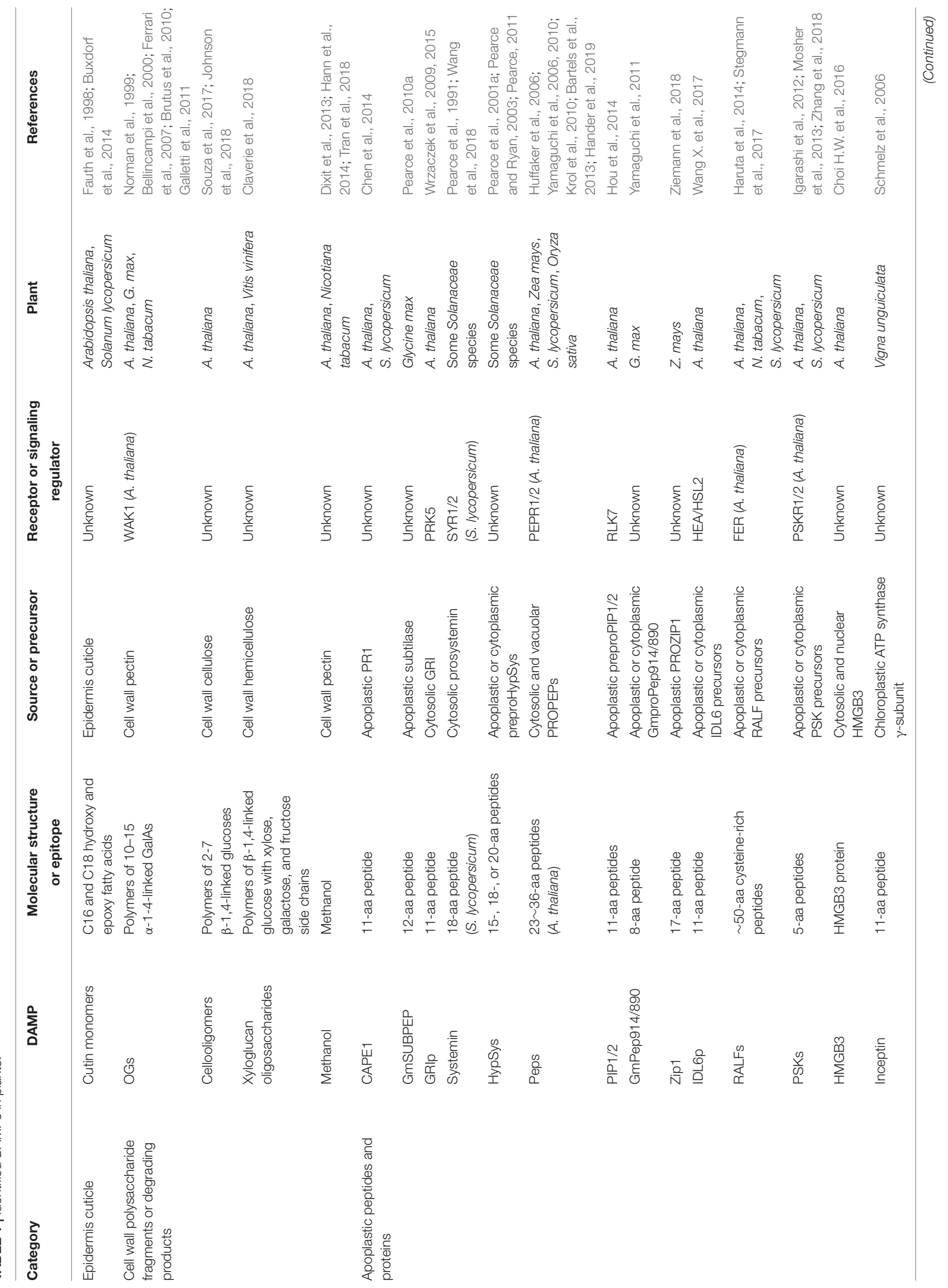




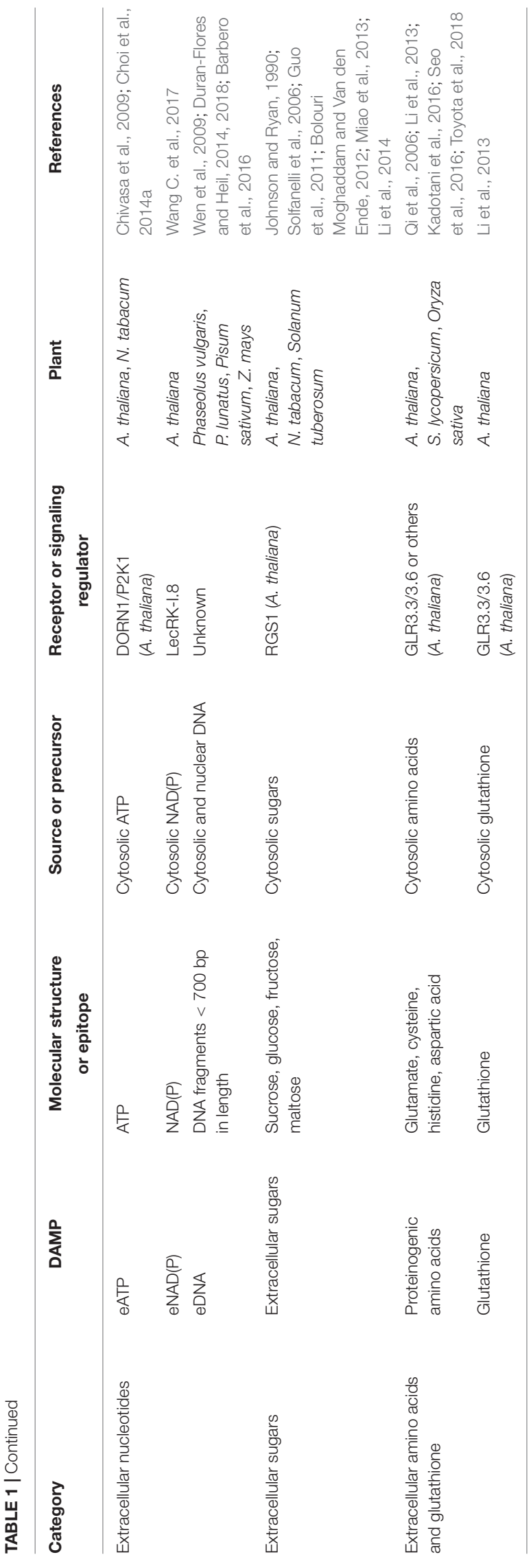

and shorter-lasting compared to induction with long OGs. Furthermore, trimers initiate a unique down-regulation of genes associated with growth and development, leading to stunted growth of seedlings to a significantly greater extent than long OGs, implying different roles between trimeric OGs and long OGs.

OGs were suggested to be perceived by WALL-ASSOCIATED KINASE 1 (WAK1) (Brutus et al., 2010), which possesses an extracellular region containing several epidermal growth factor (EGF) repeats apart from a transmembrane domain and an intracellular cytoplasmic kinase domain. Implication of WAK1 as an OG receptor was based on protein chimeras in which the intracellular kinase domain of WAK1 was exchanged for the kinase domain of EFR (Brutus et al., 2010). These chimeras produced an EFR signaling-like response after application of OGs. WAK1 overexpression in Arabidopsis enhanced OG responses and increased resistance to $B$. cinerea. Furthermore, WAK1 binds in vitro to OGs through its N-terminal non-EGF portion of the ectodomain. However, there is still absent of genetic evidence to support that WAK1 is an OG receptor. WAK1, as well as WAK2, also bind native pectin and long pectin fragments, but the affinities are lower than OGs (Decreux and Messiaen, 2005; Kohorn et al., 2006a,b, 2014). Pectin appears to induce MAPK3 phosphorylation and regulate the expression of numerous genes involved in cell expansion through WAK2 (Kohorn et al., 2009). However, pectin does not induce immune response or enhance plant resistance to pathogens (Kohorn, 2016). This further supports that plants have evolved abilities to monitor pectin integrity to trigger immunity. It is important to determine how plants distinguish OGs from pectin by using the same family receptor candidates.

\section{Cellooligomers}

Cellulose is the most abundant plant cell wall polysaccharide. A collection of $\beta$-1,4-glucan chains interact with each other via hydrogen bonds to form cellulose microfibrils. Breakdown of cellulose by microbial or plant glucosidases leads to the generation of cellooligomers, including cellobiose, cellotriose, and cellotetraose, and other short-chain $\beta$-1,4-linked D-glucoses. Arabidopsis plants exogenously treated by cellooligomers with 2-7 D-glucose repeats rapidly increase cytosolic $\mathrm{Ca}^{2+}\left(\left[\mathrm{Ca}^{2+}\right]_{\mathrm{cyt}}\right)$ and activate some other immune responses, such as immune-related gene expression, MAPK activation, and metabolism changes (Souza et al., 2017; Johnson et al., 2018). Cotreatments of cellobiose or cellotriose with chitooligomers or other PAMPs led to synergistic increases of immune responses (Souza et al., 2017; Johnson et al., 2018). It was thus speculated that the perception of cellulose-derived oligomers represents an additional layer of plant immunity following PAMP perception and plant cell wall breakdown during pathogen invasion.

Similar to OGs, the activities of cellooligomers for the induction of plant immune responses are also associated with their degrees of polymerization (Trouvelot et al., 2014). In contrast to cellobiose or other longer oligomers of Dglucose, cellotriose seems to exhibit strongest activity for induction of $\mathrm{Ca}^{2+}$ influx in Arabidopsis. In addition, cellotriose but not cellobiose can induce ROS production. The PAMP 


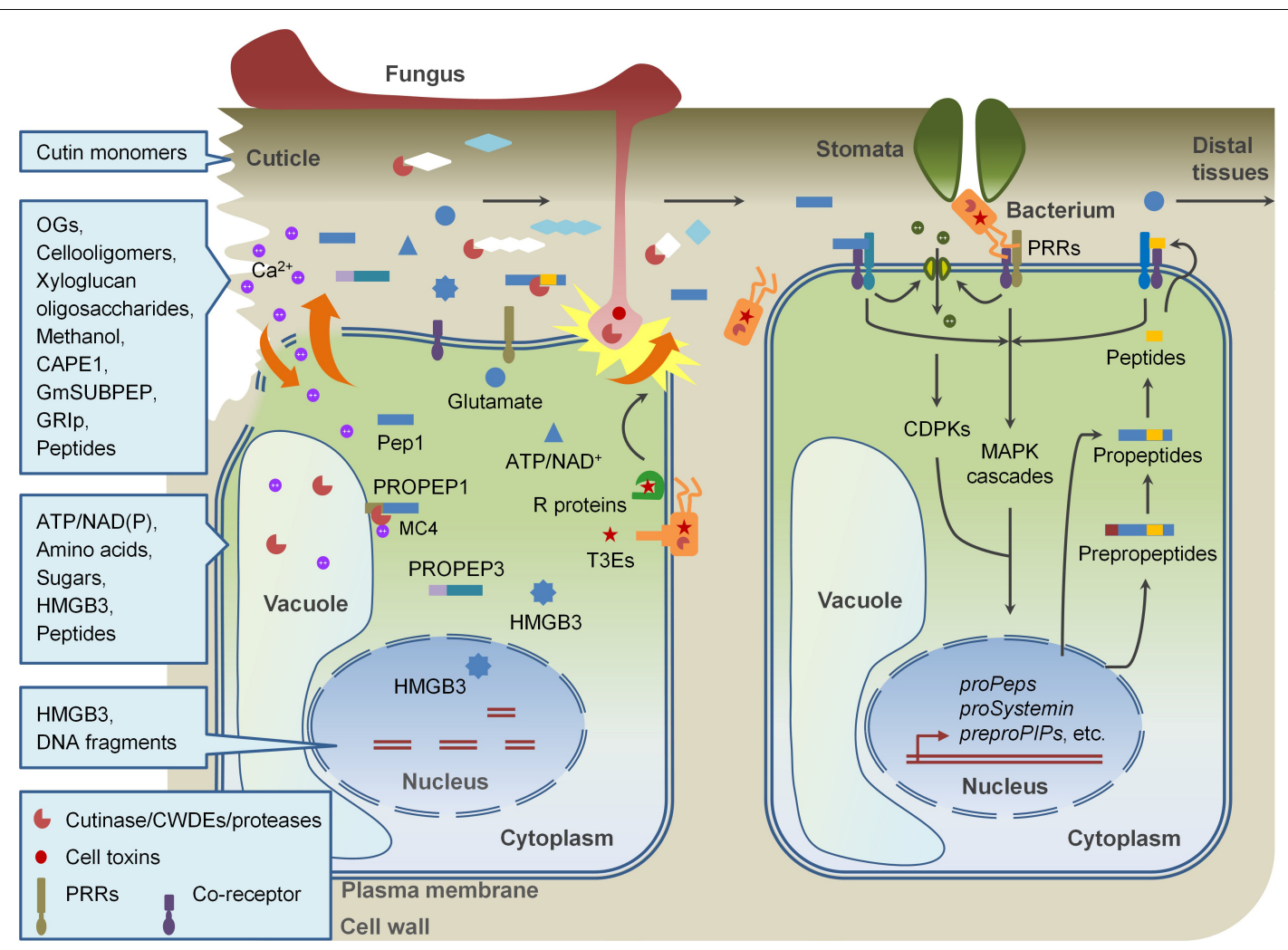

FIGURE 1 | DAMP-triggered immunity in plants. Pathogen invasion disrupts plant cell wall and plasma membrane, leading to the release of DAMPs, including fragments of cell walls and apoplastic proteins, and cytoplasmic components. Perception of DAMPs as well as PAMPs by PRRs in cells surrounding of the damaged cells also promotes the production and release of new DAMPs. These DAMPs collaborating with PAMPs modulate immune responses locally and systemically.

receptor FLS2, CHITIN ELICITOR RECEPTOR KINASE 1 (CERK1), and coreceptor BRASSINOSTEROID INSENSITIVE 1-ASSOCIATED RECEPTOR KINASE 1 (BAK1) are not required for the cellooligomer-induced calcium signaling and downstream responses in Arabidopsis (Souza et al., 2017; Johnson et al., 2018). THESEUS1 (THE1), a Catharanthus roseus RLK1-like (CrRLK1L) family RLK required for mediation of responses caused by cellulose synthesis defects does not participate in cellobiose perception (Hematy et al., 2007). Therefore, a new receptor(s) is suggested to work for specific perception of cellooligomers in Arabidopsis. A loss-of-function mutant of a poly(A) ribonuclease (PARN) shows impaired response to cellotriose and other cellooligomers, suggesting a post-transcriptional control of signaling component involved in cellooligomer-triggered immune activation (Johnson et al., 2018).

\section{Xyloglucan Oligosaccharides}

Xyloglucan is the most abundant components of hemicellulose in primary cell walls of dicotyledonous plants. It is composed of a 1,4- $\beta$-glucan backbone that is further substituted with side chains containing xylose, galactose, and fucose residues (Park and Cosgrove, 2015). A recent report demonstrated that highly purified xyloglucan oligomers obtained by enzymatic extraction and purification from apple pomace can activate immune responses, including MAPK activation, callose deposition, and immune gene expression in grapevine and Arabidopsis, resulting in the plant resistance against necrotrophic $B$. cinerea or biotrophic Hyaloperonospora arabidopsidis (Claverie et al., 2018). Therefore, it is possible that xyloglucan oligosaccharides play as DAMPs, but the mechanisms remain to be investigated further.

\section{Methanol}

Most plant-derived methanol is generated by pectin methylesterases (PMEs), which catalyze demethylesterification of the HG of cell wall pectins. Mechanical damage or herbivore attacks of plants increase the expression of PMEs and promote emission of methanol (von Dahl et al., 2006; Korner et al., 2009). Methanol is considered not only as a by-product of PME activity but also a significant signaling molecule that regulates plant resistance responses (Dorokhov et al., 2012; Komarova et al., 2014; Tran et al., 2018). It has been indicated that methanol functions as a DAMP elicitor. Methanol application for plants activates some early defense responses, including MAPK activation, $\left[\mathrm{Ca}^{2+}\right]_{\text {cyt }}$ elevation, membrane depolarization, ethylene production, and upregulation of defense gene expression, consequently enhancing resistance against pathogens or herbivorous insects (Dixit et al., 2013; Hann et al., 2014; Tran et al., 2018). Moreover, the exposure to methanol may result in a "priming" effect on immunity of uninfected leaves or neighboring plants (Hann et al., 2014). It is unclear whether 
methanol signaling is also mediated by a PRR-like receptor as some other DAMPs do.

\section{APOPLASTIC PEPTIDES AND PROTEINS}

\section{CAP-Derived Peptide 1}

Great expression of PATHOGENESIS-RELATED (PR) proteins is a typical marker of plant immune activation in various plant species. PR-1 is a member of a broader protein family known as the cysteine-rich secretory protein, antigen 5 , and pathogenesis-related-1 (CAP) protein superfamily. The protein is antimicrobial by sequestering sterols from the membranes of microbes. It is thus more effective against sterol auxotrophs, which must obtain sterols from the environment (Gamir et al., 2017). Overexpression of PR-1 in plants results in increased resistance to fungi, oomycetes, and bacteria (Sela-Buurlage et al., 1993; Niderman et al., 1995; Selitrennikoff, 2001; Sinha et al., 2014; Breen et al., 2017).

A PR1-derived peptide, named CAP-derived peptide (CAPE) 1 , was recently isolated from apoplastic fluids of tomato leaves. CAPE 1 is composed of the last 11 amino acids (aa) from the C-terminus of tomato PR-1 (Chen et al., 2014). Conserved CNYx motif positioned N-terminal to the CAPE peptide in PR-1 was confirmed to be required for the PR1 cleavage and CAPE1 release (Chen et al., 2014). CAPE1 is greatly produced in tomato leaves after damaged or pretreated with methyl jasmonate (MeJA), suggesting that an unknown protease(s) required for PR-1 cleavage and CAPE1 release is activated by wound and MeJA. Tomatoes pretreated with CAPE1 lead to the expression of multiple defense-related genes, the induction of salicylic acid (SA) and JA biosynthesis, and the enhancement of the resistance to herbivore Spodoptera litura larvae and bacterial P. syringae pv. tomato (Pst) strain DC3000. Application of a synthetic peptide predicted to be a CAPE derived from Arabidopsis PR-1 also activate the resistance against Pst DC3000 infection (Chen et al., 2014), implying that CAPE releases from PR proteins represent a conserved mechanism of plant immune regulation. However, CAPE1 cannot upregulate expression of WRKY53, which is highly upregulated in response to the application of the PAMP flg22 or some other DAMPs (Chen et al., 2014). Thus, CAPE1 may not induce the canonical PTI signaling.

\section{Glycine max SUBTILASE PEPTIDE}

Subtilisin-like proteases (SBTs) constitute a large family of extracellular plant serine proteases (Schaller et al., 2018). Some of them are involved in plant resistance to pathogens (Figueiredo et al., 2018; Hou et al., 2018). For example, tomato subtilases, P69B and P69C, are induced by pathogen attack and SA application and secreted into plant extracellular matrix to protect plants against pathogen infection (Tornero et al., 1996a,b; Jorda and Vera, 2000). AtSBT3.3, an ortholog of tomato P69C in Arabidopsis, positively regulates plant resistance to the bacterial pathogen $P$. syringae and the oomycete pathogen H. Arabidopsidis (Ramirez et al., 2013). It was reported that a 12aa peptide elicitor, named Soybean (Glycine max) SUBTILASE PEPTIDE (GmSUBPEP), was processed from a unique region of a subtilase in legume plants (Pearce et al., 2010a). Exogenous application of synthetic GmSUBPEP on soybean leaves induced expression of defense-related genes, illustrating that the peptide plays as a DAMP. How GmSUBPEP is processed and perceived to activate resistance responses in legume plants remains to be determined in the future.

\section{GRIM REAPER Peptide (GRIp)}

GRI is an Arabidopsis ortholog of the tobacco flower-specific Stig1. It was originally identified for the function in ozone response (Wrzaczek et al., 2009). A gain-of-function mutant of GRI, expressing more GRI-derived peptide, is more sensitive to ozone. Moreover, this mutant not only shows the increasing resistance to a virulent bacterial pathogen Pst DC3000, but also speeds up the induction of cell death to avirulent pathogen Pst DC3000 avrRpt2 (Wrzaczek et al., 2009). A subsequent study indicated that GRI protein is localized in extracellular spaces of Arabidopsis leaves, where it appears to be processed by METACASPASE9 (MC9) with a release of an N-terminal 11-aa peptide, GRIp. The released GRIp is perceived by the plasma membrane-localized, atypical LRR-RLK POLLENSPECIFIC RECEPTOR-LIKE KINASE 5 (PRK5), and induces SA and extracellular superoxide-dependent cell death (Wrzaczek et al., 2015). However, it is largely unclear how GRIp perception leads to the resistance to Pst DC3000.

\section{Systemin and HypSys}

Systemin is the first reported plant peptide signal, which exists in most species of the Solanaceae family including tomato and potato but excluding tobacco (Pearce et al., 1991; McGurl et al., 1992). It is an 18-aa peptide and is synthesized as a 200 -aa precursor protein named prosystemin. Prosystemin does not carry an N-terminal secretion signal sequence. It massively accumulates in the cytosol of tomato cells in response to wounding, herbivore attack or treatment with MeJA (NarvaezVasquez and Ryan, 2004). Exogenous application of systemin activates defense-related responses, including the production of protease inhibitors, the increase of ethylene and MeJA biosynthesis, the induction of an oxidative burst, and the enhancement of tomato resistance against insect herbivory (Schilmiller and Howe, 2005). Overexpression of prosystemin causes the constitutive production of protease inhibitors in plants even in the absence of wounding (Ryan and Pearce, 1998; Pearce, 2011). Thus, systemin is likely to be released through a combination of unconventional protein secretion and plant tissue injury. More recently, it was shown that the RLK SYSTEMIN RECEPTOR 1 (SYR1) acts as a systemin receptor, and both SYR1 and its homologous SYR2 are required for systemin perception in species of the Solanoideae subfamily (Wang et al., 2018). Prosystemin appears to be synthesized within the vascular bundles where wounding would release systemin in the vicinity of the phloem for the transport to other parts of the plant. As the name implies, systemin was suggested to be a mobile signal for the induction of systemic wounding signaling in some initial researches. However, it was recently indicated that systemic responses caused by mechanical damage are irrespective of the presence or absence of SYR1 and SYR2 in the tomato 
(Wang et al., 2018), implying that other long-distance signals, rather than systemin, are essential for systemic wound responses. The hydroxyproline-rich systemins (HypSys), a class of systeminlike peptides, are also produced and induce the synthesis of defensive proteinase inhibitor proteins in some Solanaceous plants like tomato and tobacco (Pearce et al., 2001a; Pearce and Ryan, 2003; Pearce, 2011). These peptides are hydroxylated, glycosylated and constitutively presented in apoplastic spaces of plants as they are originated from larger pre-proprotein precursors with signal peptides for secretion. However, HypSys do not share sequence homology with systemin, although they trigger physiological responses same as tomato systemin.

\section{Plant Elicitor Peptides (Peps)}

Plant elicitor peptide 1 (Pep1) is the first peptide elicitor identified in Arabidopsis thaliana. It is 23-aa long and derived from the carboxyl end of an approximately 100-aa long precursor protein, PROPEP1 (Huffaker et al., 2006; Yamaguchi et al., 2006). AtPep 1 promotes plant resistance to various pathogens, including bacterial Pst DC3000, fungal B. cinerea and Phytophthora infestans (Huffaker et al., 2006; Yamaguchi et al., 2010; Liu et al., 2013). Arabidopsis encodes eight PROPEP paralogs (PROPEP1-PROPEP8) that harbor conserved Pep epitopes in their C-termini. Similar to prosystemin, PROPEPs lack an $\mathrm{N}$-terminal signal sequence to enter the canonical secretory pathway (Huffaker et al., 2006; Bartels et al., 2013). Individual PROPEPs have been shown to localize to the cytosol or to be associated with the tonoplast (Bartels et al., 2013), but it is perceived outside of cells, contributing to the assumption that Peps are released into the apoplast during cell damage. A recent paper revealed that PROPEP1 is sequestered at the vacuolar membrane in the absence of damage, but it is processed by METACASPASE4 (MC4) and released only in damaged cells (Hander et al., 2019). Once cells damaged, MC4 is activated by an prolonged increase of the $\left[\mathrm{Ca}^{2+}\right]_{c y t}$ and consequently cleaves and releases the active elicitor Pep1 from PROPEP1. Pep3 seems to be greatly released out of cells in Arabidopsis seedlings challenged with virulent and avirulent bacterial pathogen $P$. syringae (Yamada et al., 2016b), implying that pathogen invasion might promote Pep maturation and extracellular release. Importantly, unprocessed PROPEP may also be released when cells are not totally disrupted as the propeptide PROPEP3 is detectable in the extracellular space of Arabidopsis seedlings upon treatment with Pep2 or isoxaben (ISX), a herbicide that blocks cellulose biosynthesis (Yamada et al., 2016b; Engelsdorf et al., 2018). Thus, Peps might be released out of cells via both unconventional secretion routes and cell damage.

Two homologous LRR-RLKs, PEP RECEPTOR 1 (PEPR1) and PEPR2, were identified as the receptors of Peps in Arabidopsis (Yamaguchi et al., 2006, 2010; Krol et al., 2010). PEPR1 is able to recognize all eight Peps, but PEPR2 detects only Pep1 and Pep2. Structural and biochemical analyses reveal that AtPep1 binds the PEPR1-LRR domain, triggers heterodimerization between PEPR1 and its coreceptor BAK1, and BAK1-dependent PEPR activation (Schulze et al., 2010; Tang et al., 2015). Once perceived, Pep1 activates various PTI responses (Huffaker et al., 2006; Ranf et al., 2011; Bartels et al., 2013; Liu et al., 2013; Ma et al., 2013;
Hou et al., 2014). Pep-PEPR1 also contributes to co-activation of SA, JA, and ethylene-mediated immune pathways (Ma et al., 2012; Flury et al., 2013; Tintor et al., 2013; Ross et al., 2014). In addition, Pep-PEPR triggers systemic immunity as well since local AtPep2 application co-activates of SA and JA-mediated responses and enhances resistance to Pst DC3000 in distal leaves, and PEPR1 and PEPR2 are required for Pst DC3000, Pst DC3000 avrRpm1 and flg22 induced systemic expression $P R$ genes or resistance to Pst DC3000 (Ross et al., 2014). It was shown that PROPEP2 and PROPEP3 are expressed in local, not in systemic leaves upon Pst DC3000 infection. PROPEP3 protein is also only detected in local but not distal leaves, excluding a possibility that Pep peptides are long-distance signals for the systemic immune activation (Ross et al., 2014).

The function of Pep family as endogenous regulators of innate immunity is conserved across diverse plant species. As an ortholog of AtPep1, maize ZmPep1 was demonstrated to promote accumulation of transcripts and metabolites associated with pathogen defense to enhance resistance against the fungal pathogens Cochliobolus heterostrophus and Colletotrichum graminicola (Huffaker et al., 2011). ZmPep1 was also proved to be perceived by ZmPEPR1, a maize ortholog of AtPEPR1 (Lori et al., 2015). In contrast, ZmPep3 as well as many Pep orthologs from other species, such as rice, soybean, and eggplant, were shown to facilitate the emission of herbivory-associated volatiles to improve the resistance to the herbivore Spodoptera exigua (Huffaker et al., 2013).

\section{GmPep914/GmPep890}

GmPep914 and GmPep890 are two 8-aa long homologous peptides. Like GmSubPep, they were isolated from leaf extracts of soybean and identified as alkalinization factors of suspension-cultured cells (Yamaguchi et al., 2011). Both peptides are processed from the C-terminus of their precursor proteins, GmPROPEP914 and GmPROPEP890, by an unknown protease(s). They can induce the expression of their precursor genes and defense genes involved in pathogen defense. Similar to prosystemins and PROPEPs, GmPROPEP914 and GmPROPEP890 have no obvious N-terminal signal sequence for secretion. It is unclear how the two peptides are released into apoplastic and perceived by cell surface-localized receptor.

\section{Zea mays Immune Signaling Peptide 1 (Zip1)}

Zea mays immune signaling peptide 1 (Zip1) is a 17-aa peptide which was isolated from apoplastic fluids of SA-pretreated leaves in maize. The peptide is processed from its propeptide precursor, PROZIP1, by papain-like cysteine proteases (PL), $\mathrm{CP} 1$ and $\mathrm{CP} 2$, -mediated protein cleavage. Zip1 treatment strongly elicits SA accumulation, induces highly overlapping transcriptional changes associated with SA-responsive genes, and confers maize an increased susceptibility toward the necrotrophic pathogen $B$. cinerea but a reduced infection of the biotrophic fungus Ustilago maydis. However, different from most DAMPs in plants, Zip1 is unable to induce rapid ROS production and MAPK phosphorylation, suggesting that Zip1 
lacks activities to activate common PTI signaling in maize. Zip1treated leaves of maize displayed strong induction of apoplastic PLCP activity comparable to the treatment by SA infiltration. Therefore, a positive feedback loop for amplification of SA signaling and ultimate immune activation was proposed, in which SA burst in plants upon pathogen infection induces PLCPsdependent release of active Zip1 from PROZIP1, Zip1 in turn induces the activity of the PLCP proteases and SA production. However, PROZIP1 transcripts are not induced by Zip1 or SA (Ziemann et al., 2018).

\section{PIP1}

PAMP-induced peptides (PIPs) represent another family of Arabidopsis peptide elicitors. The group peptides were supposed to be processed from conserved carboxyl-termini of a family of preproprotein precursors (pre-proPIPs) which were identified as MAMP-upregulated gene products. Sequences homologous to AtPIPs are found in genomes of numerous monocot and eudicot species. Arabidopsis harbors 11 members of preproPIPs, three (pre-proPIP1, pre-proPIP2, and pre-proPIP3) of which are induced by MAMPs, SA, or pathogen infection. AtPIP1 and AtPIP2, peptides corresponding to conserved carboxyltermini of preproPIP1 and preproPIP2, are able to activate PTI-like responses and amplify flg22-induced defenses, and enhance Arabidopsis resistance against Pst DC3000 and Fusarium oxysporum. As an XI subgroup of LRR-RK, RLK7, was confirmed to be a receptor of PIP1. Different from precursor proteins (systemin, Peps, and Zip1), PIP1 can be automatically secreted into extracellular spaces in a signal peptide-dependent manner and processed extracellularly into mature peptides by an unknown protease(s) (Hou et al., 2014).

\section{IDA-Like Peptides}

Like prePROPIP1, INFLORESCENCE DEFICIENT IN ABSCISSION (IDA) and IDA-LIKE 6 (IDL6) were identified as potential peptide precursor genes which are upregulated by PAMPs (Hou et al., 2014; Wang X. et al., 2017). IDL6 is one of the seven homologous proteins of IDA, the mature peptide of which was confirmed to control floral organ abscission and lateral root emergence upon perception by its receptor LRR-RK HAESA (HAE) and HAESA-LIKE2 (HSL2) (Butenko et al., 2003; Stenvik et al., 2008; Kumpf et al., 2013). IDA is mainly expressed in flower abscission zones and lateral root primordia, while IDL6 is prominently produced in Arabidopsis leaves. The expression of IDL6 is significantly upregulated by attacks of the bacterial Pst DC3000. IDL6 promotes HAE/HSL2-mediated susceptibility of Arabidopsis to Pst DC3000 by manipulating pectin digestion and inhibiting SA signaling (Wang X. et al., 2017). HAE is also expressed in abscission zones of Arabidopsis leaves upon infection with Pst DC3000. Pst DC3000 also triggers HAE/HSL2-dependent cauline leaf abscission (Patharkar et al., 2017). Therefore, an IDA family peptide might be essential for Pst DC3000-induced leaf abscission process. Furthermore, the pathogen-triggered leaf abscission was proposed to be an active defense response which is exploited by plants to prevent spread of the infection to the rest of the plant.

\section{RALFs}

RAPID ALKALINIZATION FACTORs (RALFs) are a family of cysteine-rich peptides, which are generated from pre-proproteins (Pearce et al., 2001b, 2010b). The RALF peptides contain four conserved cysteines, which are thought to form two disulfide bridges and are important for protein conformation. RALF family is wildly present across the land plants including the eudicots and the monocots. Arabidopsis genome contains a big RALF family with 39 family members. Several of them, including RALF1 and RALF23, were confirmed to be perceived by the receptor CrRLK1L RLK FERONIA (FER) (Haruta et al., 2014; Stegmann et al., 2017).

RALFs have been shown to positively and negatively regulate plant immunity. They were thus suggested to functionally resemble interleukins, a group of cytokines involved in the regulation of immune and inflammatory responses in mammals (Banchereau et al., 2012; Gust et al., 2017). In Arabidopsis, RALF23 negatively regulate PAMP responses and resistance to Pst DC3000. The inhibition of PTI is mediated by its receptor FER, which was suggested to act as a scaffold to promote the formation of active heteromeric PRR signaling complexes between the PAMP receptor FLS2 or EFR and their co-receptor BAK1 (Stegmann et al., 2017). RALF23 peptide treatment suppresses ligand-induced heteromerization between FLS2 or EFR and BAK1. The peptide is cleaved at a RRXL site by the serine protease SITE-1 PROTEASE (S1P), leading to the generation of its mature peptide which, is essential for its negative regulation of plant immunity (Srivastava et al., 2009; Stegmann et al., 2017). On the contrary, RALF17 is not cleaved by S1P and was shown to induce PTI response and promote elf18-induced PTI activation, thus contributing to Arabidopsis resistance to Pst DC3000 (Stegmann et al., 2017). Interestingly, the RALF17 function is also FER dependent. However, it is undisclosed how the two homolog peptides play reverse functions through the same receptor.

Apart from fine-tuning PTI, RALF23 perception by FER also inhibits JA signaling and thus promotes SA signaling. SA and JA function as two major immune-related hormones in plants. SA-mediated resistance is usually effective against biotrophs and hemi-biotrophs, while JA-mediated responses are predominantly against necrotrophs and herbivorous insects. Both signaling pathways are often mutually antagonistic. The transcription factor MYC2 as well as its close paralogs, MYC3 and MYC4, are key regulators of JA signaling pathway in Arabidopsis (Kazan and Manners, 2013). FER was found to inhibit JA signaling by phosphorylating and destabilizing MYC2. RALF23 can act through FER to stabilize MYC2 and enhance MYC2-mediated JA signaling, thus negatively contributing to plant immunity to biotrophs (Guo et al., 2018).

\section{Phytosulfokine}

Phytosulfokines (PSKs) are sulfated tyrosines containing pentapeptides, which are processed from approximately 80 -aa pre-propeptides by post-translational sulfation and proteolytic cleavage (Matsubayashi and Sakagami, 1996; Yang et al., 1999, 2001; Srivastava et al., 2008; Komori et al., 2009). They are ubiquitously present in higher plants. In Arabidopsis, two plasma membrane-localized LRR-RLKs PSK RECEPTOR 1 
(PSKR1) and PSKR2 are PSK receptors (Matsubayashi et al., 2006; Amano et al., 2007). Structural analyses revealed that PSK interacts mainly with the island domain embedded in PSKR extracellular LRR repeats. PSK binding promotes PSKR heterodimerization with SOMATIC EMBRYOGENESIS RECEPTOR KINASEs (SERKs), resulting in the activation of PSKR (Wang et al., 2015). In Arabidopsis, several PSKs were shown to be upregulated by the PAMP flg22 treatment (Hou et al., 2014). After perception by PSKR1/2 (mainly PSKR1), PSK attenuates PTI responses (Igarashi et al., 2012), decreases the resistance to the hemibiotrophic bacterial pathogen $P$. syringae, but enhances resistance against the necrotrophic fungal pathogen Alternaria brassicicola (Mosher et al., 2013). The PSK mediates immune regulation by suppressing the SA-mediated defense signaling but enhancing the JA-mediated defense signaling (Mosher et al., 2013). The PSK function also works in other plants. In Zinnia elegans, PSK treatment reduces the transcription of $P R$ gene $Z e P R 1$ and the protease inhibitor genes ZePI1 and ZePI2, whereas inhibition of PSK synthesis results in increased transcription of these genes (Motose et al., 2009). A recent report demonstrated that PSK acts as a DAMP and contributes to the immunity to necrotrophic fungal pathogen $B$. cinerea in tomato plants (Zhang et al., 2018). Transcription of genes encoding several PSK precursors as well as the PSK sulfation processing gene TYROSYLPROTE SULFOTRANSFERASE (TPST) was significantly upregulated by $B$. cinerea inoculation. However, unlike Arabidopsis, the PSK-mediated resistance to $B$. cinerea in tomatoes does rely on auxin-dependent immune responses but not on SA and JA signaling pathways. In mechanism, the PSK recognition by tomato PSKR1 elevated $\left[\mathrm{Ca}^{2+}\right]_{\text {cyt }}$ promote the binding between calmodulins (CaMs) and the auxin biosynthetic YUCCAs (YUCs) and facilitates the auxin accumulation, leading to the activation of auxin-mediated immunity.

\section{High Mobility Group Box-3 (HMGB3)}

HMGBs are a family of highly conserved nuclear proteins expressed in most eukaryotic cells. They participate in the organization, stabilization and repair of genomic DNA, and transcription regulation. In mammals, HMGB1 is the first biomolecule defined as a DAMP, which is released extracellularly in case of cell death or tissue injury to activate inflammatory and immune responses (Lotze and Tracey, 2005). In Arabidopsis, at least 15 genes encode HMG-box domain-containing proteins. AtHMGB3 localizes in the nucleus and cytoplasm and has been shown to be released into the extracellular spaces during the infection of the necrotrophic pathogen $B$. cinerea. Exogenous treatment with AtHMGB3 protein induces PTI responses, including MAPK activation, defense-related gene expression, callose deposition, and activates JA/ethylene-associated defenses to B. cinerea (Choi H.W. et al., 2016). Thus, AtHMGB3 was suggested to be a DAMP, which mainly protect plants against necrotrophs and insects, rather than against biotrophs and hemibiotrophs. Like its human counterpart, AtHMGB3 binds to SA, resulting in the inhibition of its DAMP activity (Choi H.W. et al., 2016). Infection with a biotrophic pathogen leads to an increase in SA levels, the elevated SA might antagonize the activation of
JA-mediated defenses in part by suppressing AtHMGB3's DAMP activity, thus directs plants to the SA-mediated resistance against biotrophic and hemi-biotrophic pathogens.

\section{Inceptin}

When cowpea (Vigna unguiculata) leaves are consumed by armyworm (Spodoptera frugiperda) larvae, a proteolysis fragment of the cowpea chloroplastic ATP synthase $\gamma$-subunit (also named cATPC protein), termed inceptin, was produced in gut of the insect (Schmelz et al., 2006). Inceptin is a disulfide-bridged peptide containing 11 amino acids. Exogenous treatment of the peptide promotes the production of immune-related hormones, ethylene, SA and JA, and defense metabolite cinnamic acid in cowpea, upregulates transcription of cowpea protease inhibitor, and enhances cowpea resistance to herbivore attacks. Sequence alignments of cATPC proteins from multiple plant species demonstrate a high degree of conservation in the amino acid sequence related to the predicted inceptin peptides. However, inceptins are active elicitors of defense responses only in one clade of the Fabaceae (Schmelz et al., 2007), suggesting that inceptin perception is a recent evolutionary event in plants.

\section{EXTRACELLULAR NUCLEOTIDES}

\section{Extracellular Adenosine 5-Triphosphate (ATP)}

ATP is a universal energy source to drive many biochemical reactions in cells. Intracellular ATP can be released into the extracellular matrix, where it is referred to as extracellular ATP (eATP), either in response to environmental stimuli or physical cell injury. In animals, eATP is considered to be a DAMP, which is perceived by two types of receptors, ligand-gated ion channel P2X and G protein-coupled P2Y, and regulate a variety of responses, such as neurotransmission, inflammation, and cell death (Khakh and Burnstock, 2009). Wounding, pathogen infection, or insect infestation also cause plants release of high level of ATP (approximate $40 \mu \mathrm{M}$ ) into the extracellular matrix, where it is recognized as a DAMP to initiate plant resistance responses (Chivasa et al., 2009; Choi et al., 2014a,b; Medina-Castellanos et al., 2014). Exogenous application of ATP triggers signaling pathways similar to the PAMP-induced plant defense responses, including elevation of $\left[\mathrm{Ca}^{2+}\right]_{\mathrm{cyt}}$, production of nitric oxide $(\mathrm{NO})$ and ROS, and MAPK phosphorylation. Gene transcriptome analysis indicated that eATP induces the expression of a large proportion of genes overlapped with those responding to wound and JA (Choi et al., 2014a; Tripathi et al., 2018; Jewell et al., 2019). eATP treatment enhances the interaction between JA receptor CORONATINE 1 (COI1) and JASMONATE ZIM-DOMAIN 1 (JAZ1), leading to a proteasome-dependent JAZ1 degradation (Tripathi et al., 2018). Therefore, eATP may promote JA signaling by eliminating JAZ1 inhibition on JA signaling. Moreover, eATP also regulates gene expression through pathways independent of COI1 but reliant on MYC transcription factors and CALMODULIN-BINDING TRANSCRIPTION ACTIVATOR 3 (CAMTA3) (Jewell et al., 2019). 
In Arabidopsis, an L-type lectin receptor kinase, DOESN OT RESPOND TO NUCLEOTIDES 1 (DORN1) (also known as $\mathrm{P} 2 \mathrm{~K} 1$ ), has been implicated in eATP sensing and signaling (Choi et al., 2014a). The extracellular legume L-type lectin domain of the DORN1/P2K1 binds ATP with high affinity, but the exact ATP binding site is still unclear. In addition to ATP, some other nucleotides, such as ADP, ATP $\gamma S$, ADP $\beta S$, GTP, UTP, and CTP, are also active in stimulation of calcium influx, but AMP and adenosine have no detectable activities (Tanaka et al., 2010). DORN1/P2K1 is required for the perception of the most nucleotides with a preference for purine nucleotides over pyrimidine nucleotides (Choi et al., 2014a).

\section{Extracellular Nicotinamide Adenine Dinucleotide (NAD) and NAD Phosphate (NADP)}

NAD and NADP are universal coenzymes, which participate in both metabolic reactions and intracellular signaling. In Arabidopsis, exogenous $\mathrm{NAD}(\mathrm{P}) \mathrm{H}$ and $\mathrm{NAD}(\mathrm{P})^{+}$were shown to activate immune responses, including $\mathrm{SA}$ accumulation, $P R$ gene expression, and enhance plant resistance to the Psm ES4326 (Wang C. et al., 2017). Transcriptome analysis revealed that NAD upregulates large number genes involved in PTI and SA signaling pathways but suppresses expression of several genes in JA/ET pathway, pointing that NAD mainly triggers plant resistance against biotrophic and hemibiotrophic pathogens. Importantly, pathogen infection and wounding commonly cause intercellular $\mathrm{NAD}(\mathrm{P})$ leakage into the extracellular space at concentrations sufficient to induce these immune responses (Wang C. et al., 2017). Thus, eNAD(P) was suggested to act as a DAMP in plants. Furthermore, eNAD $(\mathrm{P})$ was found to play a critical role in the regulation of SAR because eNAD $(\mathrm{P})$ depletion in planta through transgenic expression of the human $\mathrm{NAD}(\mathrm{P})$-metabolizing ectoenzyme CD38 compromises SAR induction by local infection with the avirulent bacterial pathogen Pst DC3000 avrRpt2. However, exogenous application of $\mathrm{NAD}(\mathrm{P})$ is unable to induce SAR, suggesting that $\operatorname{eNAD}(\mathrm{P})$ alone is not sufficient for activation of SAR (Zhang and Mou, 2012). Mutations in LecRK-I.8, a DORN1/P2K1 homologous lectin-receptor kinase, partially compromise NAD-induced immune responses and disease resistance. LecRK-I.8 has low affinity to NAD, but not affinity to ATP and $\mathrm{NADP}^{+}$, implying that LecRK-I.8 plays as a putative eNAD receptor in Arabidopsis (Wang C. et al., 2017).

\section{DNA Fragments}

DNA fragmentation and the release of the fragmented DNA occur during cell death due to pathogen infection or other stresses in plants and animals (Ryerson and Heath, 1996; Kuthanova et al., 2008). In animals, self extranuclear DNA (eDNA) released from dead cells is typical DAMP and it is perceived by TOLL-LIKE RECEPTOR 9 (TLR9) and other sensors of neighboring cells to activate innate immune responses (Gallucci and Maffei, 2017). Emerging evidences suggested that self eDNA fragments (below a size of 700 bp) also play as DAMPs to activate various PTI responses, such as membrane depolarization, $\mathrm{Ca}^{2+}$ influx, ROS generation, and MAPK activation, and increase resistance to pathogen infections in plants (Wen et al., 2009; Duran-Flores and Heil, 2014, 2018; Barbero et al., 2016). However, non-self DNA obtained from different plant species exhibits significantly lower or no detectable activities for immune activation (Duran-Flores and Heil, 2018), pointing a species-specific discrimination of self eDNA from non-self eDNA in plants. Activation of typical PTI responses by self eDNA also suggests the sensing of self eDNA depends on an PRR-like receptor(s). However, no such receptor has been definitively identified yet. The eATP receptor DORN1/P2K1 and the eNAD receptor LecRK-I.8 belong to L-type lectin receptor kinases, which are thus suggested to specifically recognize nucleotides. Therefore, it is conceivable to argue that the L-type lectin receptor kinase might be the putative receptor of plant eDNA. Further studies are required to elucidate the nature of plant eDNA receptors.

\section{EXTRACELLULAR SUGARS}

Sugars represent a group of molecules that are well-known for their roles in energy metabolism. Some bacterial and fungal pathogens assimilate the host plant-released sugars to survive and propagate in plant apoplastic spaces. To acquire abundant sugars, pathogens causes the leakage of intercellular sugars to the extracellular spaces through disintegrating plasma membrane or promoting sugar efflux into the apoplast by manipulating host plant plasma membrane-localized sugar transporters. For example, Xanthomonas bacteria deliver transcription activatorlike (TAL) effector proteins into leaf cells to induce expression of genes encoding sugar transporters to cause plant to release more sucrose (Cohn et al., 2014; Cox et al., 2017). As the opposite site, the plant also controls sugar transporter activity, to redistribute the sugars away from the infection niche, removing the energy source to limit pathogen proliferation. For instance, the recognition of the PAMP flg22 by its receptor FLS2 and coreceptor BAK1 in Arabidopsis leads to the phosphorylation of the plasma membrane SUGAR TRANSPORTER 13 (STP13) to promote its activity for monosaccharide uptake from the apoplast (Yamada et al., 2016a).

In addition to their fundamental roles as carbon and energy sources, extracellular sugars also act as signaling molecules to regulate plant resistance responses. Exogenous application of sucrose, glucose, or sucrose isomers activate MAPKs and induce the expression of several $P R$ genes (Bolouri Moghaddam and Van den Ende, 2012). Besides, sucrose, glucose, fructose, and maltose also specifically stimulate the accumulation of JA and antimicrobial agent anthocyanins, isoflavonoids, and glucosinolates in Arabidopsis (Solfanelli et al., 2006; Guo et al., 2011; Miao et al., 2013; Li et al., 2014), and enhance the expression of wound-inducible proteinase inhibitor genes in tobacco and potato tissues (Johnson and Ryan, 1990). Therefore, extracellular sugars may be recognized as DAMPs, triggering the plant defense signaling. Mounting evidence shows that extracellular sugars are sensed by REGULATOR OF 
G-PROTEIN SIGNALING 1 (RGS1), a seven-transmembrane receptor coupled with heterotrimeric G proteins (Johnston et al., 2007). It was indicated that glucose induces a WITH NO LYSINE 8 (WNK8)-dependent phosphorylation of RGS1 and a consequent endocytosis of RGS1 (Urano et al., 2012). RGS1 endocytosis leads to the physical uncoupling of RGS1 from the Arabidopsis $\mathrm{G} \alpha$ subunit, GPA1, and thus lifts the suppression on G-protein-mediated signaling. However, a direct relationship between RGS1 endocytosis and glucose-induced immune signaling has not yet built.

\section{EXTRACELLULAR AMINO ACIDS AND GLUTATHIONE}

\section{Amino Acids}

Earlier evidences for endogenous amino acids acting as extracellular signals involved in plant signaling regulation mainly based on the discovery of ionotropic glutamate receptors (iGluRs)-like genes (GLRs) in plants (Lam et al., 1998). In mammals, iGluRs as ligand-gated ion channels are gated by glutamate which is known as key neurotransmitters in the central nervous system. The plant GLRs are predicted to have similar structures as their mammalian homologs, with an $\mathrm{N}$-terminal ligand-binding domain, a transmembrane domain that includes a pore region, and a C-terminal domain. In contrast to the ligand specificity of the iGluRs, the GLR receptors in plants are gated by a broad spectrum of amino acids. At least 6 of the 20 proteinogenic amino acids, including glutamic acid, glycine, cysteine, serine, alanine, and asparagine, can serve as GLR agonists in Arabidopsis (Qi et al., 2006; Stephens et al., 2008; Li et al., 2013; Tapken et al., 2013). These amino acids trigger the membrane depolarization and the $\left[\mathrm{Ca}^{2+}\right]_{\text {cyt }}$ elevation in a GLR3.3dependent manner (Stephens et al., 2008). Among these, cysteine triggers defense responses and enhance plant resistance to pathogens through GLR3.3 in Arabidopsis. Aspartic acid cannot trigger $\left[\mathrm{Ca}^{2+}\right]_{\text {cyt }}$ elevation but increase the GLR3.3-independent resistance to Pst DC3000. Loss-of-function mutations of the Arabidopsis GLR3.3 increased susceptibility to P. syringae and H. Arabidopsidis (Li et al., 2013; Manzoor et al., 2013). In addition, histidine was also reported to induce resistance in Arabidopsis and tomato against the soil-borne bacterial pathogens Ralstonia solanacearum and B. cinerea, through activation of ethylene signaling pathway (Seo et al., 2016). Glutamic acid elevates resistance to the blast fungus Magnaporthe oryzae in rice (Kadotani et al., 2016) and the necrotrophic fungus Alternaria alternata in tomato (Yang et al., 2017), but it seems not to promote pathogen resistance in Arabidopsis (Li et al., 2013).

After sensing local herbivore attacks, plants transmit this information throughout the whole plants to rapidly enhance defense to insect herbivores in distal undamaged parts. The systemic defense was previously marked by the expression of wound-responsive marker genes and the accumulation of JA and JA-isoleucine (JA-Ile). Recent studies also detected long-distance electrical and calcium signals convert local wounding signaling (Mousavi et al., 2013; Choi W.G. et al., 2016; Toyota et al., 2018). These wound-induced systemic calcium response, as well as defense gene expression and JA and JA-Ile accumulation, are eliminated in atglr3.3/atglr3.6 double mutants (Toyota et al., 2018). The AtGLR3.3/AtGLR3.6dependent systemic calcium signaling can be mimicked by local application of glutamate instead of other amino acids (Toyota et al., 2018). Importantly, apoplastic glutamate concentration is increased by wounding, and this signal moves along the vasculature. Thus, glutamate was proposed as a DAMP, which is released into apoplastic spaces upon herbivore and mechanical damage. Released glutamate could travel long distances and activate GLR3 ion channels in the plasma membrane of cells that line the vasculature, where leading to JA accumulation and conveying host resistance to herbivory insects.

\section{Glutathione}

Reduced tripeptide glutathione (GSH) is the most abundant short-chain peptide in cells representing the major intracellular pool of endogenous non-protein thiols and protecting cell membranes against oxidative stress. In plants, pathogen infection increases the accumulation of GSH in plant cells and causes releases of the cytosolic GSH through oligopeptide transporters or disintegrating plasma membrane (Vanacker et al., 2000; Parisy et al., 2007). GSH treatment activates typical immune responses and suppresses pathogen propagation through the AtGLR3.3dependent pathway (Wingate et al., 1988; Li et al., 2013), implying that extracellular GSH represents a kind of DAMP functionally resembling amino acids.

\section{CONCLUDING REMARKS}

Plants activate the plasma membrane localized PRR-mediated immune responses through the detection of extracellular danger signals, including pathogen-derived PAMPs and plantderived DAMPs. Immune activation is energy-consumed process, which is disadvantageous to plant normal growth. To reduce losses, plant endogenous molecules which potentially play as DAMPs are produced and exposed to the surfaces of the plasma membrane and detected by PRRs when plants are suffering from pathogens invasion. The DAMPs not only contain molecules which are released on conditions of cell damage, but also include extracellular and intercellular molecules which are greatly produced, secreted, or released from their precursors without cell injury when pathogen infection. A great many researches revealed that DAMPtriggered immunity shares overlapped signaling components and functional mechanisms with PTI pathways. For example, some peptide-type DAMPs are perceived by LRR-RLKs which are close to the PAMP flagellin receptor FLS2 and EF-Tu receptor EFR. Like flagellin and EF-Tu, the perception and downstream signaling of these DAMPs usually involve BAK1, MAPK cascades, and some other PTI components. DAMPs also reprogram plant transcriptome and metabolome resembling PAMPs. In these respects, DAMPs function as PTI amplifiers. DAMP signaling also is essential for the compensation of MAMP 
signaling when MAMP-triggered defenses are compromised. In some cases, DAMPs play different roles from MAMPs. For example, PSKs and RALF23 negatively regulate PTI signaling, while CAPE1 and Zip1 act in regulation of SA signaling or other immune-related branches but not PTI responses (Figure 1). Although a significant breakthrough has been achieved during the past decade, we are still far from full elucidation of the mechanisms underlying DAMP-regulated immune signaling. The following issues are still deserved to be figured out: (i) Identifying other plant endogenous molecules which function as DAMPs and the DAMP receptors; (ii) Deciphering mechanisms used by plants to transduce DAMP signaling and achieve local or systemic resistance. (iii) Integrating the DAMP signaling with other signaling pathways involved in plant resistance to pathogens, herbivores, or abiotic stresses. These studies will help us to better understand the plant immunity system and carry out the breeding of broad-spectrum and durable disease-resistant crops in the future.

\section{REFERENCES}

Amano, Y., Tsubouchi, H., Shinohara, H., Ogawa, M., and Matsubayashi, Y. (2007). Tyrosine-sulfated glycopeptide involved in cellular proliferation and expansion in Arabidopsis. Proc. Natl. Acad. Sci. U.S.A. 104, 18333-18338. doi: 10.1073/ pnas.0706403104

Banchereau, J., Pascual, V., and O'garra, A. (2012). From IL-2 to IL-37: the expanding spectrum of anti-inflammatory cytokines. Nat. Immunol. 13, 925-931. doi: 10.1038/ni.2406

Barbero, F., Guglielmotto, M., Capuzzo, A., and Maffei, M. E. (2016). Extracellular self-DNA (esDNA), but not heterologous plant or insect DNA (etDNA), induces plasma membrane depolarization and calcium signaling in lima bean (Phaseolus lunatus) and maize (Zea mays). Int. J. Mol. Sci. 17:1659. doi: 10.3390/ ijms 17101659

Bartels, S., Lori, M., Mbengue, M., Van Verk, M., Klauser, D., Hander, T., et al. (2013). The family of Peps and their precursors in Arabidopsis: differential expression and localization but similar induction of pattern-triggered immune responses. J. Exp. Bot. 64, 5309-5321. doi: 10.1093/jxb/ert330

Bellincampi, D., Dipierro, N., Salvi, G., Cervone, F., and De Lorenzo, G. (2000). Extracellular $\mathrm{H}(2) \mathrm{O}(2)$ induced by oligogalacturonides is not involved in the inhibition of the auxin-regulated rolB gene expression in tobacco leaf explants. Plant Physiol. 122, 1379-1385. doi: 10.1104/pp.122.4.137

Benedetti, M., Pontiggia, D., Raggi, S., Cheng, Z., Scaloni, F., Ferrari, S., et al. (2015). Plant immunity triggered by engineered in vivo release of oligogalacturonides, damage-associated molecular patterns. Proc. Natl. Acad. Sci. U.S.A. 112, 5533-5538. doi: 10.1073/pnas.1504154112

Bessire, M., Borel, S., Fabre, G., Carraca, L., Efremova, N., Yephremov, A., et al. (2011). A member of the PLEIOTROPIC DRUG RESISTANCE family of ATP binding cassette transporters is required for the formation of a functional cuticle in Arabidopsis. Plant Cell 23, 1958-1970. doi: 10.1105/tpc.111. 083121

Boller, T., and Felix, G. (2009). A renaissance of elicitors: perception of microbeassociated molecular patterns and danger signals by pattern-recognition receptors. Annu. Rev. Plant. Biol. 60, 379-406. doi: 10.1146/annurev.arplant. 57.032905.105346

Bolouri Moghaddam, M. R., and Van den Ende, W. (2012). Sugars and plant innate immunity. J. Exp. Bot. 63, 3989-3998. doi: 10.1093/jxb/ers129

Breen, S., Williams, S. J., Outram, M., Kobe, B., and Solomon, P. S. (2017). Emerging insights into the functions of pathogenesis-related protein 1. Trends Plant Sci. 22, 871-879. doi: 10.1016/j.tplants.2017.06.013

Brutus, A., Sicilia, F., Macone, A., Cervone, F., and De Lorenzo, G. (2010). A domain swap approach reveals a role of the plant wall-associated kinase 1 (WAK1) as a receptor of oligogalacturonides. Proc. Natl. Acad. Sci. U.S.A. 107, 9452-9457. doi: 10.1073/pnas.1000675107

\section{AUTHOR CONTRIBUTIONS}

SH wrote the manuscript. ZL, HS, and DW revised the manuscript.

\section{FUNDING}

This work was supported by National Natural Science Foundation of China (31500971) to SH and National Key Research and Development Program of China (2017YFF0209903) to DW.

\section{ACKNOWLEDGMENTS}

We apologize to our colleagues whose work was not discussed here because of space limitations. We thank YS and the reviewers for their constructive comments on this manuscript.

Butenko, M. A., Patterson, S. E., Grini, P. E., Stenvik, G. E., Amundsen, S. S., Mandal, A., et al. (2003). Inflorescence deficient in abscission controls floral organ abscission in Arabidopsis and identifies a novel family of putative ligands in plants. Plant Cell 15, 2296-2307. doi: 10.1105/tpc.014365

Buxdorf, K., Rubinsky, G., Barda, O., Burdman, S., Aharoni, A., and Levy, M. (2014). The transcription factor SISHINE3 modulates defense responses in tomato plants. Plant Mol. Biol. 84, 37-47. doi: 10.1007/s11103-013-0117-1

Cervone, F., Hahn, M. G., De Lorenzo, G., Darvill, A., and Albersheim, P. (1989). Host-pathogen interactions: XXXIII. A plant protein converts a fungal pathogenesis factor into an ecitor of plant defense responses. Plant Physiol. 90, 542-548. doi: 10.1104/pp.90.2.542

Chassot, C., Nawrath, C., and Metraux, J. P. (2007). Cuticular defects lead to full immunity to a major plant pathogen. Plant J. 49, 972-980. doi: 10.1111/j.1365313X.2006.03017.x

Chen, Y. L., Lee, C. Y., Cheng, K. T., Chang, W. H., Huang, R. N., Nam, H. G., et al. (2014). Quantitative peptidomics study reveals that a wound-induced peptide from PR-1 regulates immune signaling in tomato. Plant Cell 26, 4135-4148. doi: 10.1105/tpc.114.131185

Chinchilla, D., Zipfel, C., Robatzek, S., Kemmerling, B., Nurnberger, T., Jones, J. D., et al. (2007). A flagellin-induced complex of the receptor FLS2 and BAK1 initiates plant defence. Nature 448, 497-500. doi: 10.1038/nature05999

Chivasa, S., Murphy, A. M., Hamilton, J. M., Lindsey, K., Carr, J. P., and Slabas, A. R. (2009). Extracellular ATP is a regulator of pathogen defence in plants. Plant J. 60, 436-448. doi: 10.1111/j.1365-313X.2009.03968.x

Choi, H. W., Manohar, M., Manosalva, P., Tian, M., Moreau, M., and Klessig, D. F. (2016). Activation of plant innate immunity by extracellular high mobility group box 3 and its inhibition by salicylic acid. PLoS Pathog. 12:e1005518. doi: 10.1371/journal.ppat.1005518

Choi, W. G., Hilleary, R., Swanson, S. J., Kim, S. H., and Gilroy, S. (2016). Rapid, long-distance electrical and calcium signaling in plants. Annu. Rev. Plant Biol. 67, 287-307. doi: 10.1146/annurev-arplant-043015-112130

Choi, J., Tanaka, K., Cao, Y., Qi, Y., Qiu, J., Liang, Y., et al. (2014a). Identification of a plant receptor for extracellular ATP. Science 343, 290-294. doi: 10.1126/ science.343.6168.290

Choi, J., Tanaka, K., Liang, Y., Cao, Y., Lee, S. Y., and Stacey, G. (2014b). Extracellular ATP, a danger signal, is recognized by DORN1 in Arabidopsis. Biochem J. 463, 429-437. doi: 10.1042/BJ20140666

Claverie, J., Balacey, S., Lemaitre-Guillier, C., Brule, D., Chiltz, A., Granet, L., et al. (2018). The cell wall-derived xyloglucan is a new DAMP triggering plant immunity in Vitis vinifera and Arabidopsis thaliana. Front. Plant Sci. 9:1725. doi: 10.3389/fpls.2018.01725

Cohn, M., Bart, R. S., Shybut, M., Dahlbeck, D., Gomez, M., Morbitzer, R., et al. (2014). Xanthomonas axonopodis virulence is promoted by a transcription activator-like effector-mediated induction of a SWEET sugar transporter in 
cassava. Mol. Plant Microbe Interact. 27, 1186-1198. doi: 10.1094/MPMI-0614-0161-R

Cote, F., and Hahn, M. G. (1994). Oligosaccharins: structures and signal transduction. Plant Mol. Biol. 26, 1379-1411. doi: 10.1007/978-94-0110239-1_9

Cox, K. L., Meng, F., Wilkins, K. E., Li, F., Wang, P., Booher, N. J., et al. (2017). TAL effector driven induction of a SWEET gene confers susceptibility to bacterial blight of cotton. Nat. Commun. 8:15588. doi: 10.1038/ncomms15588

Cui, H., Tsuda, K., and Parker, J. E. (2015). Effector-triggered immunity: from pathogen perception to robust defense. Annu. Rev. Plant Biol. 66, 487-511. doi: 10.1146/annurev-arplant-050213-040012

Davidsson, P., Broberg, M., Kariola, T., Sipari, N., Pirhonen, M., and Palva, E. T. (2017). Short oligogalacturonides induce pathogen resistance-associated gene expression in Arabidopsis thaliana. BMC Plant Biol. 17:19. doi: 10.1186/s12870016-0959-1

Davis, K. R., Darvill, A. G., Albersheim, P., and Dell, A. (1986). Host-Pathogen interactions: XXIX. Oligogalacturonides released from sodium polypectate by endopolygalacturonic acid lyase are elicitors of phytoalexins in soybean. . Plant Physiol. 80, 568-577. doi: 10.1104/pp.80.2.568

Decreux, A., and Messiaen, J. (2005). Wall-associated kinase WAK1 interacts with cell wall pectins in a calcium-induced conformation. Plant Cell Physiol. 46, 268-278. doi: 10.1093/pcp/pci026

Dixit, S., Upadhyay, S. K., Singh, H., Sidhu, O. P., Verma, P. C., and Chandrashekar, K. (2013). Enhanced methanol production in plants provides broad spectrum insect resistance. PLoS One 8:e79664. doi: 10.1371/journal. pone.0079664

Dorokhov, Y. L., Komarova, T. V., Petrunia, I. V., Frolova, O. Y., Pozdyshev, D. V., and Gleba, Y. Y. (2012). Airborne signals from a wounded leaf facilitate viral spreading and induce antibacterial resistance in neighboring plants. PLoS Pathog. 8:e1002640. doi: 10.1371/journal.ppat.1002640

Duran-Flores, D., and Heil, M. (2014). Damaged-self recognition in common bean (Phaseolus vulgaris) shows taxonomic specificity and triggers signaling via reactive oxygen species (ROS). Front. Plant Sci. 5:585. doi: 10.3389/fpls.2014. 00585

Duran-Flores, D., and Heil, M. (2018). Extracellular self-DNA as a damageassociated molecular pattern (DAMP) that triggers self-specific immunity induction in plants. Brain. Behav. Immun. 72, 78-88. doi: 10.1016/j.bbi.2017. 10.010

Engelsdorf, T., Gigli-Bisceglia, N., Veerabagu, M., McKenna, J. F., Vaahtera, L., Augstein, F., et al. (2018). The plant cell wall integrity maintenance and immune signaling systems cooperate to control stress responses in Arabidopsis thaliana. Sci. Signal 11, eaao3070. doi: 10.1126/scisignal.aao3070

Fauth, M., Schweizer, P., Buchala, A., Markstadter, C., Riederer, M., Kato, T., et al. (1998). Cutin monomers and surface wax constituents elicit $\mathrm{H} 2 \mathrm{O} 2$ in conditioned cucumber hypocotyl segments and enhance the activity of other H2O2 elicitors. Plant Physiol. 117, 1373-1380. doi: 10.1104/pp.117.4.1373

Federici, L., Di Matteo, A., Fernandez-Recio, J., Tsernoglou, D., and Cervone, F. (2006). Polygalacturonase inhibiting proteins: players in plant innate immunity? Trends Plant Sci. 11, 65-70. doi: 10.1016/j.tplants.2005.12.005

Ferrari, S., Galletti, R., Denoux, C., De Lorenzo, G., Ausubel, F. M., and Dewdney, J. (2007). Resistance to Botrytis cinerea induced in Arabidopsis by elicitors is independent of salicylic acid, ethylene, or jasmonate signaling but requires PHYTOALEXIN DEFICIENT3. Plant Physiol. 144, 367-379. doi: 10.1104/pp. 107.095596

Figueiredo, J., Sousa Silva, M., and Figueiredo, A. (2018). Subtilisin-like proteases in plant defence: the past, the present and beyond. Mol. Plant Pathol. 19, 1017-1028. doi: 10.1111/mpp. 12567

Flury, P., Klauser, D., Schulze, B., Boller, T., and Bartels, S. (2013). The anticipation of danger: microbe-associated molecular pattern perception enhances AtPeptriggered oxidative burst. Plant Physiol. 161, 2023-2035. doi: 10.1104/pp.113. 216077

Fu, Z. Q., and Dong, X. (2013). Systemic acquired resistance: turning local infection into global defense. Annu. Rev. Plant Biol. 64, 839-863. doi: 10.1146/annurevarplant-042811-105606

Galletti, R., Denoux, C., Gambetta, S., Dewdney, J., Ausubel, F. M., De Lorenzo, G., et al. (2008). The AtrbohD-mediated oxidative burst elicited by oligogalacturonides in Arabidopsis is dispensable for the activation of defense responses effective against Botrytis cinerea. Plant Physiol. 148, 1695-1706. doi: 10.1104/pp.108.127845

Galletti, R., Ferrari, S., and De Lorenzo, G. (2011). Arabidopsis MPK3 and MPK6 play different roles in basal and oligogalacturonide- or flagellin-induced resistance against Botrytis cinerea. Plant Physiol. 157, 804-814. doi: 10.1104/pp. 111.174003

Gallucci, S., and Maffei, M. E. (2017). DNA Sensing across the Tree of Life. Trends Immunol. 38, 719-732. doi: 10.1016/j.it.2017.07.012

Gamir, J., Darwiche, R., Van't Hof, P., Choudhary, V., Stumpe, M., Schneiter, R., et al. (2017). The sterol-binding activity of PATHOGENESIS-RELATED PROTEIN 1 reveals the mode of action of an antimicrobial protein. Plant J. 89, 502-509. doi: 10.1111/tpj.13398

Guo, H., Nolan, T. M., Song, G., Liu, S., Xie, Z., Chen, J., et al. (2018). FERONIA receptor kinase contributes to plant immunity by suppressing jasmonic acid signaling in Arabidopsis thaliana. Curr. Biol. 28, e3316. doi: 10.1016/j.cub.2018. 07.078

Guo, R., Yuan, G., and Wang, Q. (2011). Sucrose enhances the accumulation of anthocyanins and glucosinolates in broccoli sprouts. Food Chem. 129, 10801087. doi: 10.1016/j.foodchem.2011.05.078

Gust, A. A., Pruitt, R., and Nurnberger, T. (2017). Sensing danger: key to activating plant immunity. Trends Plant Sci. 22, 779-791. doi: 10.1016/j.tplants.2017. 07.005

Hander, T., Fernandez-Fernandez, A. D., Kumpf, R. P., Willems, P., Schatowitz, H., Rombaut, D., et al. (2019). Damage on plants activates $\mathrm{Ca}(2+)$-dependent metacaspases for release of immunomodulatory peptides. Science 363:eaar7486. doi: 10.1126/science.aar7486

Hann, C. T., Bequette, C. J., Dombrowski, J. E., and Stratmann, J. W. (2014). Methanol and ethanol modulate responses to danger- and microbe-associated molecular patterns. Front. Plant Sci. 5:550. doi: 10.3389/fpls.2014.00550

Haruta, M., Sabat, G., Stecker, K., Minkoff, B. B., and Sussman, M. R. (2014). A peptide hormone and its receptor protein kinase regulate plant cell expansion. Science 343, 408-411. doi: 10.1126/science.1244454

Heese, A., Hann, D. R., Gimenez-Ibanez, S., Jones, A. M., He, K., Li, J., et al. (2007). The receptor-like kinase SERK3/BAK1 is a central regulator of innate immunity in plants. Proc. Natl. Acad. Sci. U.S.A. 104, 12217-12222. doi: 10.1073/pnas. 0705306104

Hematy, K., Sado, P. E., Van Tuinen, A., Rochange, S., Desnos, T., Balzergue, S., et al. (2007). A receptor-like kinase mediates the response of Arabidopsis cells to the inhibition of cellulose synthesis. Curr. Biol. 17, 922-931. doi: 10.1016/j.cub. 2007.05.018

Hou, S., Jamieson, P., and He, P. (2018). The cloak, dagger, and shield: proteases in plant-pathogen interactions. Biochem. J. 475, 2491-2509. doi: 10.1042/ BCJ20170781

Hou, S., Wang, X., Chen, D., Yang, X., Wang, M., Turrà, D., et al. (2014). The secreted peptide PIP1 amplifies immunity through receptor-like kinase 7. PLoS Pathog. 10:e1004331. doi: 10.1371/journal.ppat.1004331

Huffaker, A., Dafoe, N. J., and Schmelz, E. A. (2011). ZmPep1, an ortholog of Arabidopsis elicitor peptide 1, regulates maize innate immunity and enhances disease resistance. Plant Physiol. 155, 1325-1338. doi: 10.1104/pp.110.166710

Huffaker, A., Pearce, G., and Ryan, C. A. (2006). An endogenous peptide signal in Arabidopsis activates components of the innate immune response. Proc. Natl. Acad. Sci. U.S.A. 103, 10098-10103. doi: 10.1073/pnas.0603727103

Huffaker, A., Pearce, G., Veyrat, N., Erb, M., Turlings, T. C., Sartor, R., et al. (2013). Plant elicitor peptides are conserved signals regulating direct and indirect antiherbivore defense. Proc. Natl. Acad. Sci. U.S.A. 110, 5707-5712. doi: $10.1073 /$ pnas. 1214668110

Igarashi, D., Tsuda, K., and Katagiri, F. (2012). The peptide growth factor, phytosulfokine, attenuates pattern-triggered immunity. Plant J. 71, 194-204. doi: 10.1111/j.1365-313X.2012.04950.X

Jewell, J. B., Sowders, J. M., He, R., Willis, M. A., Gang, D. R., and Tanaka, K. (2019). Extracellular ATP shapes a defense-related transcriptome both independently and along with other defense signaling pathways. Plant Physiol. 179, 1144-1158. doi: $10.1104 /$ pp.18.01301

Johnson, J. M., Thurich, J., Petutschnig, E. K., Altschmied, L., Meichsner, D., Sherameti, I., et al. (2018). A poly(A) ribonuclease controls the cellotriosebased interaction between Piriformospora indica and its host Arabidopsis. Plant Physiol. 176, 2496-2514. doi: 10.1104/pp.17.01423 
Johnson, R., and Ryan, C. A. (1990). Wound-inducible potato inhibitor II genes: enhancement of expression by sucrose. Plant Mol. Biol. 14, 527-536. doi: 10. 1007/BF00027498

Johnston, C. A., Taylor, J. P., Gao, Y., Kimple, A. J., Grigston, J. C., Chen, J. G., et al. (2007). GTPase acceleration as the rate-limiting step in Arabidopsis G protein-coupled sugar signaling. Proc. Natl. Acad. Sci. U.S.A. 104, 17317-17322. doi: $10.1073 /$ pnas.0704751104

Jorda, L., and Vera, P. (2000). Local and systemic induction of two defense-related subtilisin-like protease promoters in transgenic Arabidopsis plants. Luciferin induction of PR gene expression. Plant Physiol. 124, 1049-1058. doi: 10.1104/ pp.124.3.1049

Kadotani, N., Akagi, A., Takatsuji, H., Miwa, T., and Igarashi, D. (2016). Exogenous proteinogenic amino acids induce systemic resistance in rice. BMC Plant Biol. 16:60. doi: 10.1186/s12870-016-0748-x

Kazan, K., and Manners, J. M. (2013). MYC2: the master in action. Mol. Plant 6, 686-703. doi: $10.1093 / \mathrm{mp} / \mathrm{sss} 128$

Khakh, B. S., and Burnstock, G. (2009). The double life of ATP. Sci. Am. 301, 92.

Kohorn, B. D. (2016). Cell wall-associated kinases and pectin perception. J. Exp. Bot. 67, 489-494. doi: 10.1093/jxb/erv467

Kohorn, B. D., Johansen, S., Shishido, A., Todorova, T., Martinez, R., Defeo, E., et al. (2009). Pectin activation of MAP kinase and gene expression is WAK2 dependent. Plant J. 60, 974-982. doi: 10.1111/j.1365-313X.2009.04016.x

Kohorn, B. D., Kobayashi, M., Johansen, S., Friedman, H. P., Fischer, A., and Byers, N. (2006a). Wall-associated kinase 1 (WAK1) is crosslinked in endomembranes, and transport to the cell surface requires correct cell-wall synthesis. J. Cell Sci. 119, 2282-2290. doi: 10.1242/jcs.02968

Kohorn, B. D., Kobayashi, M., Johansen, S., Riese, J., Huang, L. F., Koch, K., et al. (2006b). An Arabidopsis cell wall-associated kinase required for invertase activity and cell growth. Plant J. 46, 307-316. doi: 10.1111/j.1365-313X.2006. 02695.x

Kohorn, B. D., Kohorn, S. L., Saba, N. J., and Martinez, V. M. (2014). Requirement for pectin methyl esterase and preference for fragmented over native pectins for wall-associated kinase-activated. EDS1/PAD4-dependent stress response in Arabidopsis. J. Biol. Chem. 289, 18978-18986. doi: 10.1074/jbc.M114. 567545

Komarova, T. V., Sheshukova, E. V., and Dorokhov, Y. L. (2014). Cell wall methanol as a signal in plant immunity. Front. Plant Sci. 5:101. doi: 10.3389/ fpls.2014.00101

Komori, R., Amano, Y., Ogawa-Ohnishi, M., and Matsubayashi, Y. (2009). Identification of tyrosylprotein sulfotransferase in Arabidopsis. Proc. Natl. Acad. Sci. U.S.A. 106, 15067-15072. doi: 10.1073/pnas.0902801106

Korner, E., Von Dahl, C. C., Bonaventure, G., and Baldwin, I. T. (2009). Pectin methylesterase NaPME1 contributes to the emission of methanol during insect herbivory and to the elicitation of defence responses in Nicotiana attenuata. J. Exp. Bot. 60, 2631-2640. doi: 10.1093/jxb/erp106

Krol, E., Mentzel, T., Chinchilla, D., Boller, T., Felix, G., Kemmerling, B., et al. (2010). Perception of the Arabidopsis danger signal peptide 1 involves the pattern recognition receptor AtPEPR1 and its close homologue AtPEPR2. J. Biol. Chem. 285, 13471-13479. doi: 10.1074/jbc.M109. 097394

Kubicek, C. P., Starr, T. L., and Glass, N. L. (2014). Plant cell wall-degrading enzymes and their secretion in plant-pathogenic fungi. Annu. Rev. Phytopathol. 52, 427-451. doi: 10.1146/annurev-phyto-102313-045831

Kumpf, R. P., Shi, C. L., Larrieu, A., Sto, I. M., Butenko, M. A., Péret, B., et al. (2013). Floral organ abscission peptide IDA and its HAE/HSL2 receptors control cell separation during lateral root emergence. Proc. Natl. Acad. Sci. U.S.A. 110, 5235-5240. doi: 10.1073/pnas.1210835110

Kurdyukov, S., Faust, A., Nawrath, C., Bar, S., Voisin, D., Efremova, N., et al. (2006). The epidermis-specific extracellular BODYGUARD controls cuticle development and morphogenesis in Arabidopsis. Plant Cell 18, 321-339. doi: $10.1105 /$ tpc. 105.036079

Kuthanova, A., Opatrny, Z., and Fischer, L. (2008). Is internucleosomal DNA fragmentation an indicator of programmed death in plant cells? J. Exp. Bot. 59, 2233-2240. doi: 10.1093/jxb/ern090

Lam, H. M., Chiu, J., Hsieh, M. H., Meisel, L., Oliveira, I. C., Shin, M., et al. (1998). Glutamate-receptor genes in plants. Nature 396, 125-126. doi: 10.1038/ 24066
Li, F., Wang, J., Ma, C., Zhao, Y., Wang, Y., Hasi, A., et al. (2013). Glutamate receptor-like channel3.3 is involved in mediating glutathionetriggered cytosolic calcium transients, transcriptional changes, and innate immunity responses in Arabidopsis. Plant Physiol. 162, 1497-1509. doi: 10.1104/ pp.113.217208

Li, Y., Van Den Ende, W., and Rolland, F. (2014). Sucrose induction of anthocyanin biosynthesis is mediated by DELLA. Mol. Plant 7, 570-572. doi: 10.1093/mp/ sst161

Liu, Z., Wu, Y., Yang, F., Zhang, Y., Chen, S., Xie, Q., et al. (2013). BIK1 interacts with PEPRs to mediate ethylene-induced immunity. Proc. Natl. Acad. Sci. U.S.A. 110, 6205-6210. doi: 10.1073/pnas.1215543110

Lori, M., Van Verk, M. C., Hander, T., Schatowitz, H., Klauser, D., Flury, P., et al. (2015). Evolutionary divergence of the plant elicitor peptides (Peps) and their receptors: interfamily incompatibility of perception but compatibility of downstream signalling. J. Exp. Bot. 66, 5315-5325. doi: 10.1093/jxb/erv236

Lotze, M. T., and Tracey, K. J. (2005). High-mobility group box 1 protein (HMGB1): nuclear weapon in the immune arsenal. Nat. Rev. Immunol. 5, 331-342. doi: 10.1038/nri1594

Lotze, M. T., Zeh, H. J., Rubartelli, A., Sparvero, L. J., Amoscato, A. A., Washburn, N. R., et al. (2007). The grateful dead: damage-associated molecular pattern molecules and reduction/oxidation regulate immunity. Immunol. Rev. 220, 60-81. doi: 10.1111/j.1600-065X.2007.00579.x

Ma, Y., Walker, R. K., Zhao, Y., and Berkowitz, G. A. (2012). Linking ligand perception by PEPR pattern recognition receptors to cytosolic $\mathrm{Ca} 2+$ elevation and downstream immune signaling in plants. Proc. Natl. Acad. Sci. U.S.A. 109, 19852-19857. doi: 10.1073/pnas.1205448109

Ma, Y., Zhao, Y., Walker, R. K., and Berkowitz, G. A. (2013). Molecular steps in the immune signaling pathway evoked by plant elicitor peptides: $\mathrm{Ca} 2+$-dependent protein kinases, nitric oxide, and reactive oxygen species are downstream from the early Ca2+ signal. Plant Physiol. 163, 1459-1471. doi: 10.1104/pp.113. 226068

Macho, A. P., and Zipfel, C. (2014). Plant PRRs and the activation of innate immune signaling. Mol. Cell 54, 263-272. doi: 10.1016/j.molcel.2014.03.028

Manzoor, H., Kelloniemi, J., Chiltz, A., Wendehenne, D., Pugin, A., Poinssot, B., et al. (2013). Involvement of the glutamate receptor AtGLR3.3 in plant defense signaling and resistance to Hyaloperonospora arabidopsidis. Plant J. 76, 466480. doi: $10.1111 /$ tpj.12311

Matsubayashi, Y., Ogawa, M., Kihara, H., Niwa, M., and Sakagami, Y. (2006). Disruption and overexpression of Arabidopsis phytosulfokine receptor gene affects cellular longevity and potential for growth. Plant Physiol. 142, 45-53. doi: 10.1104/pp.106.081109

Matsubayashi, Y., and Sakagami, Y. (1996). Phytosulfokine, sulfated peptides that induce the proliferation of single mesophyll cells of Asparagus officinalis L. Proc. Natl. Acad. Sci. U.S.A. 93, 7623-7627. doi: 10.1073/pnas.93. 15.7623

McGurl, B., Pearce, G., Orozco-Cardenas, M., and Ryan, C. A. (1992). Structure, expression, and antisense inhibition of the systemin precursor gene. Science 255, 1570-1573. doi: 10.1126/science. 1549783

Medina-Castellanos, E., Esquivel-Naranjo, E. U., Heil, M., and Herrera-Estrella, A. (2014). Extracellular ATP activates MAPK and ROS signaling during injury response in the fungus Trichoderma atroviride. Front. Plant Sci. 5:659. doi: 10.3389/fpls.2014.00659

Miao, H., Wei, J., Zhao, Y., Yan, H., Sun, B., Huang, J., et al. (2013). Glucose signalling positively regulates aliphatic glucosinolate biosynthesis. J. Exp. Bot. 64, 1097-1109. doi: 10.1093/jxb/ers399

Mosher, S., Seybold, H., Rodriguez, P., Stahl, M., Davies, K. A., Dayaratne, S., et al. (2013). The tyrosine-sulfated peptide receptors PSKR1 and PSY1R modify the immunity of Arabidopsis to biotrophic and necrotrophic pathogens in an antagonistic manner. Plant J. 73, 469-482. doi: 10.1111/tpj.12050

Motose, H., Iwamoto, K., Endo, S., Demura, T., Sakagami, Y., Matsubayashi, Y., et al. (2009). Involvement of phytosulfokine in the attenuation of stress response during the transdifferentiation of zinnia mesophyll cells into tracheary elements. Plant Physiol. 150, 437-447. doi: 10.1104/pp.109. 135954

Mousavi, S. A., Chauvin, A., Pascaud, F., Kellenberger, S., and Farmer, E. E. (2013). GLUTAMATE RECEPTOR-LIKE genes mediate leaf-to-leaf wound signalling. Nature 500, 422-426. doi: 10.1038/nature 12478 
Narvaez-Vasquez, J., and Ryan, C. A. (2004). The cellular localization of prosystemin: a functional role for phloem parenchyma in systemic wound signaling. Planta 218, 360-369. doi: 10.1007/s00425-003-1115-3

Niderman, T., Genetet, I., Bruyere, T., Gees, R., Stintzi, A., Legrand, M., et al. (1995). Pathogenesis-related PR-1 proteins are antifungal. Isolation and characterization of three 14-kilodalton proteins of tomato and of a basic PR-1 of tobacco with inhibitory activity against Phytophthora infestans. Plant Physiol. 108, 17-27. doi: 10.1104/pp.108.1.17

Norman, C., Vidal, S., and Palva, E. T. (1999). Oligogalacturonide-mediated induction of a gene involved in jasmonic acid synthesis in response to the cellwall-degrading enzymes of the plant pathogen Erwinia carotovora. Mol. Plant Microbe Interact. 12, 640-644. doi: 10.1094/MPMI.1999.12.7.640

Orozco-Cardenas, M., and Ryan, C. A. (1999). Hydrogen peroxide is generated systemically in plant leaves by wounding and systemin via the octadecanoid pathway. Proc. Natl. Acad. Sci. U.S.A. 96, 6553-6557. doi: 10.1073/pnas.96.11. 6553

Parisy, V., Poinssot, B., Owsianowski, L., Buchala, A., Glazebrook, J., and Mauch, F. (2007). Identification of PAD2 as a gamma-glutamylcysteine synthetase highlights the importance of glutathione in disease resistance of Arabidopsis. Plant J. 49, 159-172. doi: 10.1111/j.1365-313X.2006.02938.x

Park, Y. B., and Cosgrove, D. J. (2015). Xyloglucan and its interactions with other components of the growing cell wall. Plant Cell Physiol. 56, 180-194. doi: $10.1093 /$ pcp/pcu204

Patharkar, O. R., Gassmann, W., and Walker, J. C. (2017). Leaf shedding as an anti-bacterial defense in Arabidopsis cauline leaves. PLoS Genet. 13:e1007132. doi: 10.1371/journal.pgen.1007132

Pearce, G. (2011). Systemin, hydroxyproline-rich systemin and the induction of protease inhibitors. Curr. Protein Pept. Sci. 12, 399-408. doi: 10.2174/ 138920311796391106

Pearce, G., Moura, D. S., Stratmann, J., and Ryan, C. A. (2001a). Production of multiple plant hormones from a single polyprotein precursor. Nature 411, 817-820. doi: $10.1038 / 35081107$

Pearce, G., and Ryan, C. A. (2003). Systemic signaling in tomato plants for defense against herbivores. Isolation and characterization of three novel defensesignaling glycopeptide hormones coded in a single precursor gene. J. Biol. Chem. 278, 30044-30050. doi: 10.1074/jbc.M304159200

Pearce, G., Strydom, D., Johnson, S., and Ryan, C. A. (1991). A polypeptide from tomato leaves induces wound-inducible proteinase inhibitor proteins. Science 253, 895-897. doi: 10.1126/science.253.5022.895

Pearce, G., Yamaguchi, Y., Barona, G., and Ryan, C. A. (2010a). A subtilisinlike protein from soybean contains an embedded, cryptic signal that activates defense-related genes. Proc. Natl. Acad. Sci. U.S.A. 107, 14921-14925. doi: 10. 1073/pnas. 1007568107

Pearce, G., Yamaguchi, Y., Munske, G., and Ryan, C. A. (2010b). Structure-activity studies of RALF, rapid alkalinization factor, reveal an essential-YISY-motif. Peptides 31, 1973-1977. doi: 10.1016/j.peptides.2010.08.012

Pearce, G., Moura, D. S., Stratmann, J., and Ryan, C. A. Jr. (2001b). RALF, a 5-kDa ubiquitous polypeptide in plants, arrests root growth and development. Proc. Natl. Acad. Sci. U.S.A 98, 12843-12847. doi: 10.1073/pnas.201416998

Qi, Z., Stephens, N. R., and Spalding, E. P. (2006). Calcium entry mediated by GLR3.3, an Arabidopsis glutamate receptor with a broad agonist profile. Plant Physiol. 142, 963-971. doi: 10.1104/pp.106.088989

Ramirez, V., Lopez, A., Mauch-Mani, B., Gil, M. J., and Vera, P. (2013). An extracellular subtilase switch for immune priming in Arabidopsis. PLoS Pathog. 9:e1003445. doi: 10.1371/journal.ppat.1003445

Ranf, S., Eschen-Lippold, L., Pecher, P., Lee, J., and Scheel, D. (2011). Interplay between calcium signalling and early signalling elements during defence responses to microbe- or damage-associated molecular patterns. Plant J. 68, 100-113. doi: 10.1111/j.1365-313X.2011.04671.x

Reis, H., Pfiffi, S., and Hahn, M. (2005). Molecular and functional characterization of a secreted lipase from Botrytis cinerea. Mol. Plant Pathol. 6, 257-267. doi: 10.1111/j.1364-3703.2005.00280.x

Ross, A., Yamada, K., Hiruma, K., Yamashita-Yamada, M., Lu, X., Takano, Y., et al. (2014). The Arabidopsis PEPR pathway couples local and systemic plant immunity. EMBO J. 33, 62-75. doi: 10.1002/embj.201284303

Ryan, C. A., and Pearce, G. (1998). Systemin: a polypeptide signal for plant defensive genes. Annu. Rev. Cell Dev. Biol. 14, 1-17. doi: 10.1146/annurev. cellbio.14.1.1
Ryerson, D. E., and Heath, M. C. (1996). Cleavage of nuclear DNA into oligonucleosomal fragments during cell death induced by fungal infection or by abiotic treatments. Plant Cell 8, 393-402. doi: 10.1105/tpc.8.3.393

Schaller, A., Stintzi, A., Rivas, S., Serrano, I., Chichkova, N. V., Vartapetian, A. B., et al. (2018). From structure to function - a family portrait of plant subtilases. New Phytol. 218, 901-915. doi: 10.1111/nph.14582

Schilmiller, A. L., and Howe, G. A. (2005). Systemic signaling in the wound response. Curr. Opin. Plant Biol. 8, 369-377. doi: 10.1016/j.pbi.2005.05.008

Schmelz, E. A., Carroll, M. J., Leclere, S., Phipps, S. M., Meredith, J., Chourey, P. S., et al. (2006). Fragments of ATP synthase mediate plant perception of insect attack. Proc. Natl. Acad. Sci. U.S.A. 103, 8894-8899. doi: 10.1073/pnas. 0602328103

Schmelz, E. A., Leclere, S., Carroll, M. J., Alborn, H. T., and Teal, P. E. (2007). Cowpea chloroplastic ATP synthase is the source of multiple plant defense elicitors during insect herbivory. Plant Physiol. 144, 793-805. doi: 10.1104/pp. 107.097154

Schulze, B., Mentzel, T., Jehle, A. K., Mueller, K., Beeler, S., Boller, T., et al. (2010). Rapid heteromerization and phosphorylation of ligand-activated plant transmembrane receptors and their associated kinase BAK1. J. Biol. Chem. 285, 9444-9451. doi: 10.1074/jbc.M109.096842

Sela-Buurlage, M. B., Ponstein, A. S., Bres-Vloemans, S. A., Melchers, L. S., Van Den Elzen, P., and Cornelissen, B. (1993). Only specific tobacco (Nicotiana tabacum) chitinases and [beta]-1,3-glucanases exhibit antifungal activity. Plant Physiol. 101, 857-863. doi: 10.1104/pp.101.3.857

Selitrennikoff, C. P. (2001). Antifungal proteins. Appl. Environ. Microbiol. 67, 2883-2894. doi: 10.1128/AEM.67.7.2883-2894.2001

Seo, S., Nakaho, K., Hong, S. W., Takahashi, H., Shigemori, H., and Mitsuhara, I. (2016). 1-histidine induces resistance in plants to the bacterial pathogen Ralstonia solanacearum partially through the activation of ethylene signaling. Plant Cell Physiol. 57, 1932-1942. doi: 10.1093/pcp/pcw114

Seong, S. Y., and Matzinger, P. (2004). Hydrophobicity: an ancient damageassociated molecular pattern that initiates innate immune responses. Nat. Rev. Immunol. 4, 469-478. doi: 10.1038/nri1372

Serrano, M., Coluccia, F., Torres, M., L'haridon, F., and Metraux, J. P. (2014). The cuticle and plant defense to pathogens. Front. Plant Sci. 5:274. doi: 10.3389/fpls. 2014.00274

Sinha, M., Singh, R. P., Kushwaha, G. S., Iqbal, N., Singh, A., Kaushik, S., et al. (2014). Current overview of allergens of plant pathogenesis related protein families. Scientific World J. 2014:543195. doi: 10.1155/2014/543195

Solfanelli, C., Poggi, A., Loreti, E., Alpi, A., and Perata, P. (2006). Sucrosespecific induction of the anthocyanin biosynthetic pathway in Arabidopsis. Plant Physiol. 140, 637-646. doi: 10.1104/pp.105.072579

Souza, C. A., Li, S., Lin, A. Z., Boutrot, F., Grossmann, G., Zipfel, C., et al. (2017). Cellulose-derived oligomers act as damage-associated molecular patterns and trigger defense-like responses. Plant Physiol. 173, 2383-2398. doi: 10.1104/pp. 16.01680

Srivastava, R., Liu, J. X., Guo, H., Yin, Y., and Howell, S. H. (2009). Regulation and processing of a plant peptide hormone. AtRALF23, in Arabidopsis. Plant J. 59, 930-939. doi: 10.1111/j.1365-313X.2009.03926.x

Srivastava, R., Liu, J. X., and Howell, S. H. (2008). Proteolytic processing of a precursor protein for a growth-promoting peptide by a subtilisin serine protease in Arabidopsis. Plant J. 56, 219-227. doi: 10.1111/j.1365-313X.2008. 03598.x

Stegmann, M., Monaghan, J., Smakowska-Luzan, E., Rovenich, H., Lehner, A., Holton, N., et al. (2017). The receptor kinase FER is a RALF-regulated scaffold controlling plant immune signaling. Science 355, 287-289. doi: 10.1126/science. aal2541

Stenvik, G. E., Tandstad, N. M., Guo, Y., Shi, C. L., Kristiansen, W., Holmgren, A., et al. (2008). The EPIP peptide of INFLORESCENCE DEFICIENT IN ABSCISSION is sufficient to induce abscission in Arabidopsis through the receptor-like kinases HAESA and HAESA-LIKE2. Plant Cell 20, 1805-1817. doi: $10.1105 /$ tpc. 108.059139

Stephens, N. R., Qi, Z., and Spalding, E. P. (2008). Glutamate receptor subtypes evidenced by differences in desensitization and dependence on the GLR3.3 and GLR3.4 genes. Plant Physiol. 146, 529-538. doi: 10.1104/pp.107.108134

Sun, Y., Li, L., Macho, A. P., Han, Z., Hu, Z., Zipfel, C., et al. (2013). Structural basis for flg22-induced activation of the Arabidopsis FLS2-BAK1 immune complex. Science 342, 624-628. doi: 10.1126/science.1243825 
Tanaka, K., Choi, J., Cao, Y., and Stacey, G. (2014). Extracellular ATP acts as a damage-associated molecular pattern (DAMP) signal in plants. Front. Plant Sci. 5:446. doi: 10.3389/fpls.2014.00446

Tanaka, K., Swanson, S. J., Gilroy, S., and Stacey, G. (2010). Extracellular nucleotides elicit cytosolic free calcium oscillations in Arabidopsis. Plant Physiol. 154, 705-719. doi: 10.1104/pp.110.162503

Tang, J., Han, Z., Sun, Y., Zhang, H., Gong, X., and Chai, J. (2015). Structural basis for recognition of an endogenous peptide by the plant receptor kinase PEPR1. Cell Res. 25, 110-120. doi: 10.1038/cr.2014.161

Tapken, D., Anschutz, U., Liu, L. H., Huelsken, T., Seebohm, G., Becker, D., et al. (2013). A plant homolog of animal glutamate receptors is an ion channel gated by multiple hydrophobic amino acids. Sci. Signal. 6:ra47. doi: 10.1126/scisignal. 2003762

Tintor, N., Ross, A., Kanehara, K., Yamada, K., Fan, L., Kemmerling, B., et al. (2013). Layered pattern receptor signaling via ethylene and endogenous elicitor peptides during Arabidopsis immunity to bacterial infection. Proc. Natl. Acad. Sci. U.S.A. 110, 6211-6216. doi: 10.1073/pnas.1216780110

Tornero, P., Conejero, V., and Vera, P. (1996a). Primary structure and expression of a pathogen-induced protease (PR-P69) in tomato plants: similarity of functional domains to subtilisin-like endoproteases. Proc. Natl. Acad. Sci. U.S.A. 93, 6332-6337. doi: 10.1073/pnas.93.13.6332

Tornero, P., Mayda, E., Gomez, M. D., Canas, L., Conejero, V., and Vera, P. (1996b). Characterization of LRP, a leucine-rich repeat (LRR) protein from tomato plants that is processed during pathogenesis. Plant J. 10, 315-330. doi: 10.1046/j.1365-313X.1996.10020315.X

Toyota, M., Spencer, D., Sawai-Toyota, S., Jiaqi, W., Zhang, T., Koo, A. J., et al. (2018). Glutamate triggers long-distance, calcium-based plant defense signaling. Science 361, 1112-1115. doi: 10.1126/science.aat7744

Tran, D., Dauphin, A., Meimoun, P., Kadono, T., Nguyen, H. T. H., ArbeletBonnin, D., et al. (2018). Methanol induces cytosolic calcium variations membrane depolarization and ethylene production in Arabidopsis and tobacco. Ann. Bot. 122, 849-860. doi: 10.1093/aob/mcy038

Tripathi, D., Zhang, T., Koo, A. J., Stacey, G., and Tanaka, K. (2018). Extracellular ATP acts on jasmonate signaling to reinforce plant defense. Plant Physiol. 176, 511-523. doi: 10.1104/pp.17.01477

Trouvelot, S., Heloir, M. C., Poinssot, B., Gauthier, A., Paris, F., Guillier, C., et al. (2014). Carbohydrates in plant immunity and plant protection: roles and potential application as foliar sprays. Front. Plant Sci. 5:592. doi: 10.3389/fpls. 2014.00592

Urano, D., Phan, N., Jones, J. C., Yang, J., Huang, J., Grigston, J., et al. (2012). Endocytosis of the seven-transmembrane RGS1 protein activates G-proteincoupled signalling in Arabidopsis. Nat. Cell Biol. 14, 1079-1088. doi: 10.1038/ ncb2568

Vanacker, H., Carver, T. L., and Foyer, C. H. (2000). Early H(2)O(2) accumulation in mesophyll cells leads to induction of glutathione during the hyper-sensitive response in the barley-powdery mildew interaction. Plant Physiol. 123, 12891300. doi: 10.1104/pp.123.4.1289

von Dahl, C. C., Havecker, M., Schlogl, R., and Baldwin, I. T. (2006). Caterpillarelicited methanol emission: a new signal in plant-herbivore interactions? Plant J. 46, 948-960. doi: 10.1111/j.1365-313X.2006.02760.x

Wang, C., Zhou, M., Zhang, X., Yao, J., Zhang, Y., and Mou, Z. (2017). A lectin receptor kinase as a potential sensor for extracellular nicotinamide adenine dinucleotide in Arabidopsis thaliana. Elife 6:e25474. doi: 10.7554/eLife.25474

Wang, X., Hou, S., Wu, Q., Lin, M., Acharya, B. R., Wu, D., et al. (2017). IDL6HAE/HSL2 impacts pectin degradation and resistance to Pseudomonas syringae pv tomato DC3000 in Arabidopsis leaves. Plant J. 89, 250-263. doi: 10.1111/tpj. 13380

Wang, J., Li, H., Han, Z., Zhang, H., Wang, T., Lin, G., et al. (2015). Allosteric receptor activation by the plant peptide hormone phytosulfokine. Nature 525 , 265-268. doi: 10.1038/nature14858

Wang, L., Einig, E., Almeida-Trapp, M., Albert, M., Fliegmann, J., Mithöfer, A., et al. (2018). The systemin receptor SYR1 enhances resistance of tomato against herbivorous insects. Nat. Plants 4, 152-156. doi: 10.1038/s41477-018-0106-0

Wen, F., White, G. J., Vanetten, H. D., Xiong, Z., and Hawes, M. C. (2009). Extracellular DNA is required for root tip resistance to fungal infection. Plant Physiol. 151, 820-829. doi: 10.1104/pp.109.142067
Wingate, V. P., Lawton, M. A., and Lamb, C. J. (1988). Glutathione causes a massive and selective induction of plant defense genes. Plant Physiol. 87, 206-210. doi: $10.1104 /$ pp.87.1.206

Wrzaczek, M., Brosche, M., Kollist, H., and Kangasjarvi, J. (2009). Arabidopsis GRI is involved in the regulation of cell death induced by extracellular ROS. Proc. Natl. Acad. Sci. U.S.A. 106, 5412-5417. doi: 10.1073/pnas.0808980106

Wrzaczek, M., Vainonen, J. P., Stael, S., Tsiatsiani, L., Help-Rinta-Rahko, H., Gauthier, A., et al. (2015). GRIM REAPER peptide binds to receptor kinase PRK5 to trigger cell death in Arabidopsis. EMBO J. 34, 55-66. doi: 10.15252/ embj.201488582

Yamada, K., Saijo, Y., Nakagami, H., and Takano, Y. (2016a). Regulation of sugar transporter activity for antibacterial defense in Arabidopsis. Science 354, 1427-1430. doi: 10.1126/science.aah5692

Yamada, K., Yamashita-Yamada, M., Hirase, T., Fujiwara, T., Tsuda, K., Hiruma, K., et al. (2016b). Danger peptide receptor signaling in plants ensures basal immunity upon pathogen-induced depletion of BAK1. EMBO J. 35, 46-61. doi: 10.15252/embj.201591807

Yamaguchi, Y., Barona, G., Ryan, C. A., and Pearce, G. (2011). GmPep914, an eight-amino acid peptide isolated from soybean leaves, activates defense-related genes. Plant Physiol. 156, 932-942. doi: 10.1104/pp.111.173096

Yamaguchi, Y., Huffaker, A., Bryan, A. C., Tax, F. E., and Ryan, C. A. (2010). PEPR2 is a second receptor for the Pep1 and Pep2 peptides and contributes to defense responses in Arabidopsis. Plant Cell 22, 508-522. doi: 10.1105/tpc.109. 068874

Yamaguchi, Y., Pearce, G., and Ryan, C. A. (2006). The cell surface leucine-rich repeat receptor for AtPep1, an endogenous peptide elicitor in Arabidopsis, is functional in transgenic tobacco cells. Proc. Natl. Acad. Sci. U.S.A. 103, 10104-10109. doi: 10.1073/pnas.0603729103

Yang, H., Matsubayashi, Y., Nakamura, K., and Sakagami, Y. (1999). Oryza sativa PSK gene encodes a precursor of phytosulfokine-alpha, a sulfated peptide growth factor found in plants. Proc. Natl. Acad. Sci. U.S.A 96, 13560-13565. doi: 10.1073/pnas.96.23.13560

Yang, H., Matsubayashi, Y., Nakamura, K., and Sakagami, Y. (2001). Diversity of Arabidopsis genes encoding precursors for phytosulfokine, a peptide growth factor. Plant Physiol. 127, 842-851. doi: 10.1104/pp.010452

Yang, J., Sun, C., Fu, D., and Yu, T. (2017). Test for l-glutamate inhibition of growth of Alternaria alternata by inducing resistance in tomato fruit. Food Chem. 230, 145-153. doi: 10.1016/j.foodchem.2017.03.033

Yu, X., Feng, B., He, P., and Shan, L. (2017). From chaos to harmony: responses and signaling upon microbial pattern recognition. Annu. Rev. Phytopathol. 55, 109-137. doi: 10.1146/annurev-phyto-080516-035649

Zhang, H., Hu, Z., Lei, C., Zheng, C., Wang, J., Shao, S., et al. (2018). A plant phytosulfokine peptide initiates auxin-dependent immunity through cytosolic $\mathrm{Ca}(2+)$ signaling in tomato. Plant Cell 30, 652-667. doi: 10.1105/tpc.17. 00537

Zhang, X., and Mou, Z. (2012). Expression of the human NAD(P)-metabolizing ectoenzyme CD38 compromises systemic acquired resistance in Arabidopsis. Mol. Plant Microbe Interact. 25, 1209-1218. doi: 10.1094/MPMI-1011-0278

Ziemann, S., Van Der Linde, K., Lahrmann, U., Acar, B., Kaschani, F., Colby, T., et al. (2018). An apoplastic peptide activates salicylic acid signalling in maize. Nat. Plants 4, 172-180. doi: 10.1038/s41477-018-0116-y

Ziv, C., Zhao, Z., Gao, Y. G., and Xia, Y. (2018). Multifunctional roles of plant cuticle during plant-pathogen interactions. Front. Plant Sci. 9:1088. doi: 10. 3389/fpls.2018.01088

Conflict of Interest Statement: The authors declare that the research was conducted in the absence of any commercial or financial relationships that could be construed as a potential conflict of interest.

Copyright (c) $2019 \mathrm{Hou}$, Liu, Shen and Wu. This is an open-access article distributed under the terms of the Creative Commons Attribution License (CC BY). The use, distribution or reproduction in other forums is permitted, provided the original author(s) and the copyright owner(s) are credited and that the original publication in this journal is cited, in accordance with accepted academic practice. No use, distribution or reproduction is permitted which does not comply with these terms. 